\title{
The MISTIGRI thermal infrared project: scientific objectives and mission specifications
}

\author{
Jean-Pierre Lagouarde ${ }^{a *}$, Michel Bach $^{\mathrm{b}}$, José A. Sobrino $^{\mathrm{c}}$, Gilles Boulet ${ }^{\mathrm{d}}$, \\ Xavier Briottet $^{\mathrm{e}}$, Selma Cherchali ${ }^{\mathrm{b}}$, Benoit Coudert ${ }^{\mathrm{d}}$, Isabelle Dadouf ${ }^{\mathrm{f}}$, Gérard Dedieu $^{\mathrm{d}}$, \\ Philippe Gamet $^{\mathrm{b}}$, Olivier Hagolle ${ }^{\mathrm{d}}$, Frédéric Jacob ${ }^{\mathrm{g}}$, Françoise Nerry ${ }^{\mathrm{h}}$, Albert Olioso ${ }^{\mathrm{i}}$, \\ Catherine Ottléj, Jean-louis Roujean ${ }^{\mathrm{k}}$, and Guy Fargant ${ }^{1}$ \\ ${ }^{a}$ Institut National de la Recherche Agronomique, UR1263 EPHYSE, F-33140 Villenave d'Ornon, \\ France; ${ }^{b}$ Centre National d'Etudes Spatiales (CNES), F-31401 Toulouse Cedex 9, France; ' $U C G$ / \\ IPL, Universidad de Valencia, E-46071 Valencia, Spain; ${ }^{d}$ Centre d'Etudes Spatiales de la BIOsphere \\ (CNRS, UPS, CNES, IRD), F-31401 Toulouse Cedex 9, France; ${ }^{e}$ Office National d'Etudes et \\ Recherches Aérospatiales-DOTA, BP 74025, F-31055 Toulouse Cedex 4, France; ${ }^{f}$ Laboratoire \\ d'Etudes en Géophysique et Océanographie Spatiales (LEGOS) (CNES/CNRS/IRD/UPS), OMP, \\ F-31400 Toulouse Cedex, France; ${ }^{g}$ Institut de Recherche pour le Développement-LISAH, F-34060 \\ Montpellier Cedex 1, France; ${ }^{h}$ Laboratoire des Sciences de l'Image, de l'Informatique et de la \\ Télédétection/TRIO, F-67412 Illkirch Cedex, France; ${ }^{i}$ Institut National de la Recherche \\ Agronomique-EMMAH, UMR 1114, F-84 914 Avignon Cedex 9, France; ${ }^{j}$ Centre d'Etudes de Saclay, \\ Orme des Merisiers, LSCE-IPSL, F-9119 Gif-sur-Yvette, France; ${ }^{k}$ Météo France CNRM-GAME, \\ F-31057 Toulouse, France; 'Thales Alenia Space, BP 99 - 06156 Cannes la Bocca, France
}

\begin{abstract}
This article presents the MISTIGRI project of a microsatellite developed by the French space agency Centre National d'Etudes Spatiales (CNES) in cooperation with Spain (Image Processing Laboratory of the University of Valencia and Centro para el Desarrollo Tecnológico Industrial (CDTI)). MISTIGRI is a mission that has the originality of combining a high spatial resolution $(\sim 50 \mathrm{~m})$ with a daily revisit in the thermal infrared (TIR). MISTIGRI is an experimental mission devoted to demonstrate the potential of such TIR data for future operational missions. The scientific goals and expected applications of the mission are described: they encompass the monitoring of (i) agricultural areas and related hydrological processes, (ii) urban areas, and (iii) coastal areas and continental waters. Then, the specifications on spatial resolution, revisit frequency, overpass time, and spectral configuration are justified. The strategy of the mission is based on the combination with a network of long-term experimental sites. It will also make possible observing some areas facing rapid climatic change. The choice of the orbit is presented. Finally, we give rapid overviews of both the instrumental concept and the proposed mission architecture.
\end{abstract}

\section{Introduction}

It is now largely recognized that man interacts very strongly and very rapidly with the environment at all spatial and temporal scales through agricultural practices, landscape organization, urbanization, emissions of pollutants, and greenhouse gases, among others (IPCC 2007 report). The interactions between water and carbon cycles and climate 
processes are subsequently affected. Indeed, the exchanges of water, carbon dioxide $\left(\mathrm{CO}_{2}\right)$, and energy between the surface and the atmosphere largely drive a number of processes such as vegetation growth, soil moisture dynamics, ocean circulation, biogeochemical cycles, etc., which in turn exert strong feedback effects on climate. This makes the implementation of operational methods for monitoring land-use changes, vegetation dynamics, surface energy, and water budgets necessary. The Micro Satellite for Thermal Infrared Ground Surface Imaging (MISTIGRI) mission described in this article focuses on the latter.

Surface temperature $\left(T_{\mathrm{s}}\right)$ is a key signature of the surface energy budget. It can be directly related to the surface energy fluxes, especially to latent heat flux (i.e. evapotranspiration, ET) and water deficit (Courault, Seguin, and Olioso 2005; Boulet et al. 2007; Kalma, McVicar, and McCabe 2008, among others). Many methods have been proposed to use TIR remote sensing for monitoring the surface conditions and for developing practical applications in different fields such as agriculture, hydrology, meteorology, oceanography, climatology, etc. Nevertheless, researchers and end-users still have to face a dilemma between spatial and temporal resolution. On the one hand, systems such as the Advanced Very High Resolution Radiometer (AVHRR), Météosat Seconde Génération (MSG), and Moderate Resolution Imaging Spectroradiometer (MODIS) provide daily observations with low (e.g. kilometric) spatial resolution. On the other hand, systems such as Landsat or the Advanced Spaceborne Thermal Emission and Reflection Radiometer (ASTER) provide high spatial resolution with poor revisit capabilities of about 2 weeks. Over land surfaces, several attempts have been made to disaggregate lowresolution imagery down to a few tens of metres (Agam et al. 2007; Inamdar et al. 2008; Inamdar and French 2009; Merlin et al. 2010, 2012), with the scope of exploiting the daily revisit of AVHRR, MODIS, or Meteorological Satellite (METEOSAT) systems, making possible the monitoring of rapid changes in relation with rainfall or irrigation for instance. But despite some progress, the results are not robust enough, partly because it is difficult to account for the variability of the various fields within the coarse resolution pixel: in particular, fields covered with the same crop may display important differences in water status and ET rates, in relation to irrigation or soil hydrodynamic properties.

Significant improvements in the modelling and monitoring of the vegetation/climate system, particularly at local scale, are now expected from the availability of new spaceborne land surface temperature (LST) observational techniques that provide both (i) high revisit capabilities and (ii) high spatial resolution. This is the goal of the MISTIGRI mission, designed to associate a high resolution of $50 \mathrm{~m}$ and a daily revisit. In the visible and near-infrared (VNIR) solar domain, the need of data combining high spatial resolution and daily revisit has been recognized for a long time: the offer of data already exists with FORMOSAT-2 and will be soon extended with the ORFEO/PLEIADES, SENTINEL-2 and Ven $\mu$ s satellites.

\section{Scientific objectives}

MISTIGRI is a so-called 'demonstration' mission, which aims to develop and validate methodologies and products in order to prepare future operational missions in the TIR. Three main scientific objectives drive the MISTIGRI mission. MISTIGRI has first been designed for the monitoring of energy and water budgets of the continental biosphere. The second objective deals with energy balance and climatology within urban areas and the third with the monitoring of coastal areas and continental waters. Additional applications requiring TIR data could also benefit from MISTIGRI observations, such as volcanology, coal mine fires, propagation of human diseases, etc. 
Methodological progress is also expected from MISTIGRI data, among which are (i) the study of aggregation processes and scaling, which should in turn contribute to an improved use of the low-resolution data of the global cover sensors such as AVHRR or MODIS, (ii) the determination of emissivity and temperature-emissivity separation (Becker and Li 1990; Dash et al. 2002; Jacob et al. 2008), and (iii) the study of directional anisotropy (Lagouarde et al. 2000, Kurz 2009, 2010).

\subsection{Monitoring of energy and water budgets of the continental biosphere}

The first objective of MISTIGRI is to contribute to the monitoring of the water cycle, with a particular emphasis on the assessment at the field scale of the rapid changes in land surface water status, after rainfall or irrigation. A first set of immediate applications in agriculture deals with the detection of water deficit and the estimation of ET, both of which provide information about water needs, irrigation optimization, $\mathrm{CO}_{2}$ absorption, vegetation growth, and crop yield. Additionally, the water transfers within the soil-plant-atmosphere continuum are strongly linked to the transfers of different minerals and chemical elements, which makes ET a strong determinant in biogeochemical cycles. Finally, the field of hydrology is also concerned, since ET drives surface and root-zone soil moisture through plant water extraction, with consequences on watershed hydrological responses through surface runoff and subsurface infiltration.

Much research has been done on the estimation of ET since the 1960s, resulting in a large panel of mature models and approaches that are now available for developing MISTIGRI-derived ET products. The orbit chosen for MISTIGRI (see Section 5.2) offers a very limited number of locations where day and night tracks cross each other. This makes approaches based on thermal inertia unsuitable, and limits the panel of possibilities to algorithms based on a single daytime measurement of surface temperature.

A first class of simplified approaches for estimating and mapping ET is based on using the spatial variability within limits determined from an analysis of the spatial relationships between $T_{\mathrm{s}}$ and albedo (or the normalized difference vegetation index (NDVI)). Provided the consideration of the model sensitivity limits, the advantage of such methods lies in the fact that they require little additional input data only. The algorithms currently used are SEBAL (Bastiaanssen et al. 1998, 2005; Jacob et al. 2002a; French et al. 2005; Courault et al. 2009), S-SEBI (Roerink, Su, and Menenti 2000; Gómez et al. 2005; Galleguillos et al. 2011a), SEBS (Su 2002; Oku, Shikawa, and Zhongbo 2007; Van der Kwast et al. 2009), METRIC (Allen, Tasumi, and Trezza 2007), WDI (Moran et al. 1994, 1996; Galleguillos et al. 2011b), and the triangle approach (Jiang and Islam 1999; Tang, Li, and Tang 2010). A review can be found in Carlson (2007) and Kalma, McVicar, and McCabe (2008). Figure 1, which displays an ET map derived from airborne AHS scanner data and S-SEBI model over the Barrax agricultural area in Spain, provides an example of retrieved fluxes that can be expected from MISTIGRI. Temporal interpolation of ET maps between dates when TIR data are available is then necessary to ensure a continuous monitoring of water status, whereas assimilating ET into hydrological models can improve their calibration and initialization (Schuurmans et al. 2003). Reconstruction of the daily cumulative ET on the day of satellite acquisition is usually achieved by assuming self-preservation of the evaporative fraction (EF) during the course of the day. EF is the ratio between the instantaneous latent heat flux and the available energy computed as the difference between instantaneous values of the net radiation and the soil heat flux. Daily ET for days without satellite acquisition can be similarly computed by estimating available energy during those days and interpolating linearly EF values between two successive TIR images. 

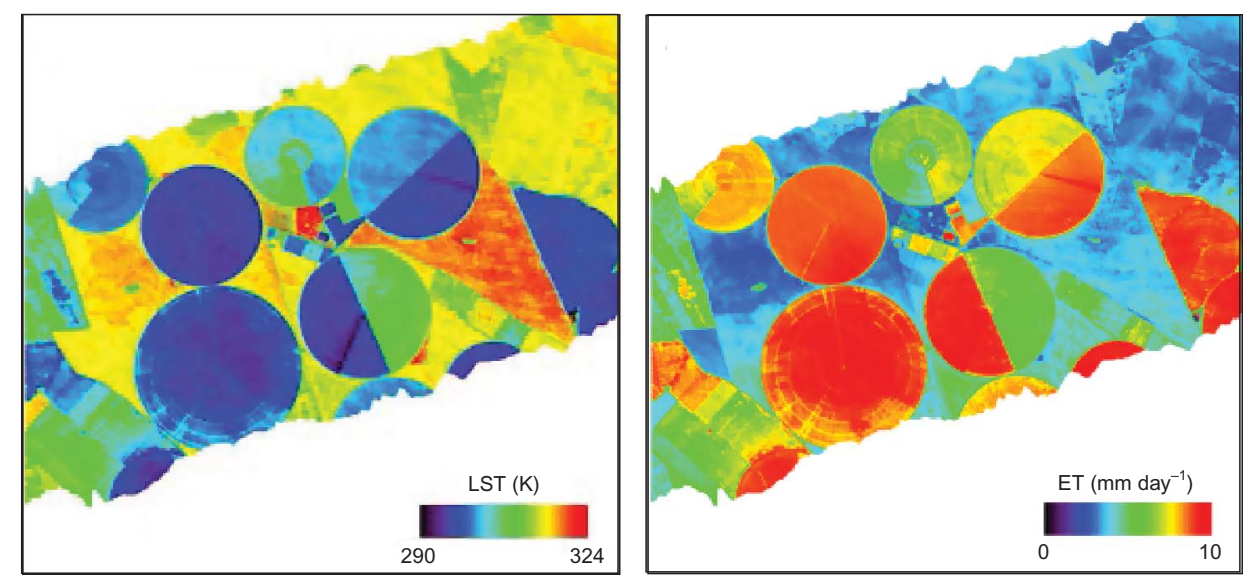

Figure 1. Land surface temperature (LST) and daily evapotranspiration (ET) retrieved from airborne hyperspectral scanner (AHS) data along with the S-SEBI model, over the Barrax agricultural area (Spain) in the framework of the SEN2FLEX-2005 campaign (after Sobrino et al. 2008). The studied area is about $4 \mathrm{~km}$ long by $1.8 \mathrm{~km}$ wide, and is centred on $39^{\circ} 03^{\prime} 40^{\prime \prime} \mathrm{N}$ and $02^{\circ} 05^{\prime} 57^{\prime \prime} \mathrm{W}$.

Aside from the previous approaches, more sophisticated ones consist of using biophysical Soil-Vegetation-Atmosphere Transfer (SVAT) models associated with inversion (Carlson et al. 1981) and assimilation procedures. Assimilation techniques provide wellestablished mathematical frameworks for introducing information on observation and model errors, and on a priori information. They have been proposed for retrieving model parameters (soil hydrodynamic properties, stomatal conductance parameters, etc.) or initial values of model variables (e.g. soil water and nitrogen content, sowing date, etc.) using model calibration techniques (Olioso et al. 1999, 2005; Coudert and Ottlé 2007). Another way of using SVAT models with remote-sensing data consist of correcting the time course of model variables (soil moisture, leaf area index (LAI), biomass, etc.) by comparing model simulations to remote-sensing measurements each time the latter are available (Ottlé, VidalMadjar, and Girard 1989; Pellenq and Boulet 2002; Crow, Kustas, and Prueger 2008). Their application to soil-vegetation-climate interactions models was rather limited until now, given the lack of adequate TIR data and the necessity to develop adapted assimilation techniques that account for the low-resolution and low-repetitivity characteristics of the actual instruments.

With regards to the above-mentioned materials, MISTIGRI is expected to stimulate applications in various fields, which are listed below.

\subsubsection{Agriculture, forestry, and ecology}

Significant improvements are expected in the retrieval of soil moisture and ET dynamics for managing water resources in irrigated agricultural areas. It is particularly important in a context where, according to the United Nations and World Bank, irrigated areas should cover $70 \%$ of the world food demand towards 2025 . More efficient practices for a better scheduling of field-scale irrigations are required at the extent of irrigated perimeters or watersheds, in particular in situations when a limited amount of water is available (e.g. deficit irrigation systems). This makes TIR remote sensing quite necessary, particularly for areas with poor availability of monitoring network. Such is the case, for example, of the dry 
lands of the Western Africa Sahelian zone, which is characterized since the 1970s by erratic climatic changes/fluctuations that have profound impacts on both natural ecosystems and agricultural production (Fensholt et al. 2006).

In forestry, TIR data can help to detect water deficit, which opens a large panel of applications, including the monitoring of tree growth and wood production, as well as the assessment of fire risk. Anticipating water deficit can also mitigate the risk of diseases, and thus secure the economic potential of forestry (Jang, Viau, and Anctil 2006).

MISTIGRI should also help to monitor other factors with potentially important applications, such as detection of frost in agroclimatology, or characterization of microclimates in ecology, etc. It could also possibly contribute to the detection and mapping of seasonally frozen ground in northern regions, which is an important indicator of global warming processes (Comiso 2003; Hachem, Allard, and Duguay 2009).

These few examples of applications show that the complementary use of MISTIGRI observations together with other sources of data (satellites, ground networks, meteorological reanalysis products, etc.) should become a key component in detection systems designed to provide regular information on the seasonal development of vegetation and on its productivity.

\subsubsection{Biogeochemical cycles and soil pollution}

By the information brought on ET and water fluxes at local scale when used in combination with SVAT models, MISTIGRI will directly contribute to improve our understanding and monitoring of the biogeochemical cycles. For instance, SVAT models for volatile organic compounds or nitrogen oxides $\left(\mathrm{NO}_{x}\right)$ will benefit from MISTIGRI observations on water exchanges in relation to vegetation transpiration and stomatal closure (Kramm et al. 1996; Cortinovis et al. 2004). Other applications will be explored, such as the soil pollutant dynamics through the processes of degradation and mobilization of chemical inputs, which have been shown to be driven by both soil moisture content and surface temperature (Alletto et al. 2006; Louchart and Voltz 2007).

\subsubsection{Hydrology and meteorology}

By governing the water cycle and energy transport within the biosphere, atmosphere, and hydrosphere, ET plays an important role in hydrology and meteorology. In particular, ET appears as a key factor in prediction and estimation of regional-scale surface runoff and underground water flows, which interact with large-scale atmospheric circulation and global climate change. This explains the importance that has been given to the ET processes within most of the international programmes focusing on hydrology and meteorology (e.g. HAPEX Sahel, http://www.cesbio.ups-tlse.fr/hapex/; SALSA, http://www. tucson.ars.ag.gov/salsa/salsahome.html; AMMA, http://amma.mediasfrance.org/; HyMeX, http://www.hymex.org/; SICMED, http://www.sicmed.net/, etc.). MISTIGRI should therefore contribute to provide reliable information on land surface ET when (i) natural hazards such as floods and droughts are predicted and (ii) weather forecasting and climate change modelling are performed (Brutsaert 1986).

\subsection{Monitoring of the urban environment}

The climate over cities is significantly affected by a number of characteristics that belong to urban areas. The three-dimensional (3D) structure of urban canopies with important heterogeneities both at local scale (building heights, street orientations, etc.) and at larger scale 
(districts designed for settlement, industry, commerce, etc.) alter the roughness of the surface and the flow within the urban atmospheric boundary layer. The use of a large panel of artificial materials with contrasted surface properties also affects the radiative transfers, while the reduction of vegetated areas and the increase of impervious surface combine to drastically modify water cycles. Human activities also contribute to urban climate in several ways: urbanization, emission of pollutants, and increase of energy consumption, among others. This finally results in a strong variability of microclimates inside cities and in differences with surrounding rural climate, the well-known urban heat island (UHI) phenomena.

Since the end of the 1990s, much progress has been made on the modelling of surface energy budget at local scale (Voogt and Oke 2003; Hénon 2008; Hénon et al. 2009) and at mesoscale (Martilli, Clappier, and Rotach 2002; Masson 2006). For instance, Figure 2 shows a recent simulation of the 3D canopy surface temperature over a small district of Toulouse, together with the comparison against airborne data acquired on the same area (Hénon et al. 2009). Although model calibration is still needed to reduce differences between simulations and observations, these results provide an example of the type of tool which will be soon available and on which the interpretation of MISTIGRI data will rely. Methods based on the use of 3D descriptions of the urban canopy also allow describing the TIR directional anisotropy (Soux et al. 2004; Lagouarde et al. 2010). Simultaneously, several models focusing on the radiative transfer have been proposed (Belot 2007; Fontanilles et al. 2008). The aggregation processes of facets temperatures and emissivities can be studied using codes such as TITAN (Fontanilles et al. 2008). A large panel of modelling tools adapted to urban canopies is now available. It allows relating the measurements from space to the surface characteristics and fluxes, which had remained a difficulty for a long time (Roth, Oke, and Emery 1989). With regards to the above-mentioned materials, the fields of application of MISTIGRI are listed below.

\subsubsection{Urban climatology and heat waves}

The increase of the frequency and intensity of heat waves expected as a consequence of climate change makes necessary policies for mitigating their effects (reduction of the

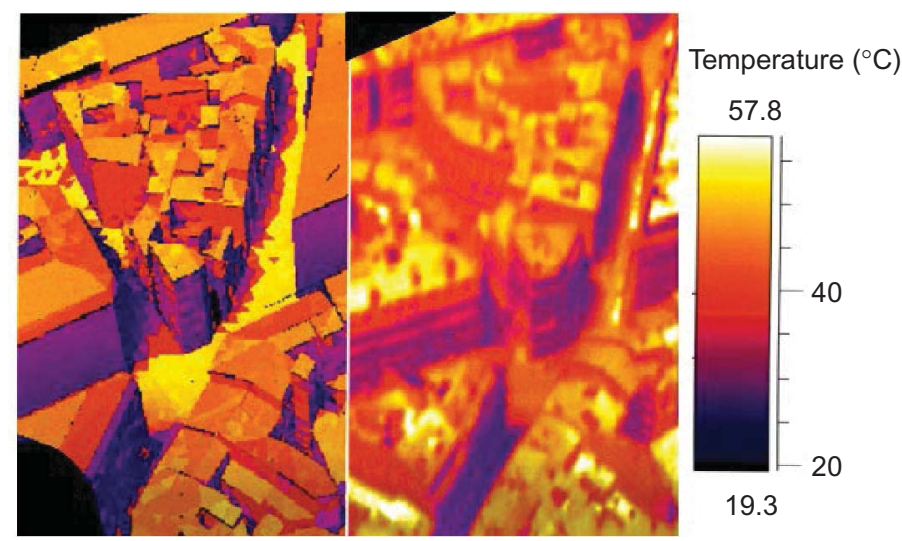

Figure 2. Comparison of the canopy surface temperature over a district of Toulouse city (performed in the framework of the CAPITOUL experiment, 2004) around 14:00 UTC simulated by the SOLENE model and measured using an airborne FLIR SC2000 TIR camera (after Hénon et al. 2009). The studied area, about $160 \times 100 \mathrm{~m}$ wide, is situated at $43^{\circ} 36^{\prime} 12^{\prime \prime} \mathrm{N}$ and $01^{\circ} 26^{\prime} 44^{\prime \prime} \mathrm{E}$, close to the Capitole square, in the centre of the city. 
number of casualties among the elderly, adaptation to energy consumption increase with the use of air conditioning, etc.). A strong demand now exists for building alert systems and improved urban planning. The important literature on UHI (Arnfield 2003) and recent articles on heat waves (Dousset et al. 2011 for instance) confirm the potential of TIR remote sensing.

\subsubsection{Urban hydrology}

Accurate estimations and mapping of ET are expected for a better assessment of the water budgets of urban watersheds (Carlson and Arthur 2000) and for urban planning.

\subsubsection{Monitoring of urban vegetation}

Vegetation plays a significant role in hydrology (by increasing water storage capacities of ground and limiting runoff) and in the welfare and health of inhabitants (humidification of air, shading effects and reduction of temperatures, etc.). TIR observations will provide information on the vegetation energetic and hydric status, with implications for urban hydrology and climate.

\subsubsection{Diffusion of pollutants and air quality}

The surface temperature here brings an indirect but important contribution by the fact that it provides boundary conditions to help constrain the atmospheric flow and diffusion models used for predicting the air quality and its spatial variations.

2.2.5. Anthropogenic fluxes (industrial activity, air conditioning, or heating of buildings, transport, etc.)

A few recent studies reveal they can be estimated through the closure of the surface energy budgets (Kato and Yamaguchi 2005; Pigeon et al. 2007).

\subsection{Monitoring of coastal and continental waters}

Sea surface temperature (SST) at the ocean-atmosphere interface represents a key variable for understanding, monitoring, and predicting fluxes of heat, momentum, and gases as well as oceanic dynamics (physics and biogeochemistry) at a large range of scales. In coastal areas, the intense exchanges between ocean, atmosphere, and land generate a very large variability of surface temperature both in time and space, which makes MISTIGRI data suitable for a variety of applications.

\subsubsection{Air-sea fluxes and winds}

In coastal areas, several processes are responsible for possibly intense SST gradients at small scale lower than $1 \mathrm{~km}$ (for instance, fresh water coming from rivers or estuaries). These strong gradients influence air-sea fluxes and winds (Chelton, Schlax, and Samelson 2007; Donlon et al. 2009). MISTIGRI will allow following the SST gradients displayed by such fronts, which is not possible with current satellite data. Figure 3 gives an example of SST gradients that could be captured with spatial resolution finer 

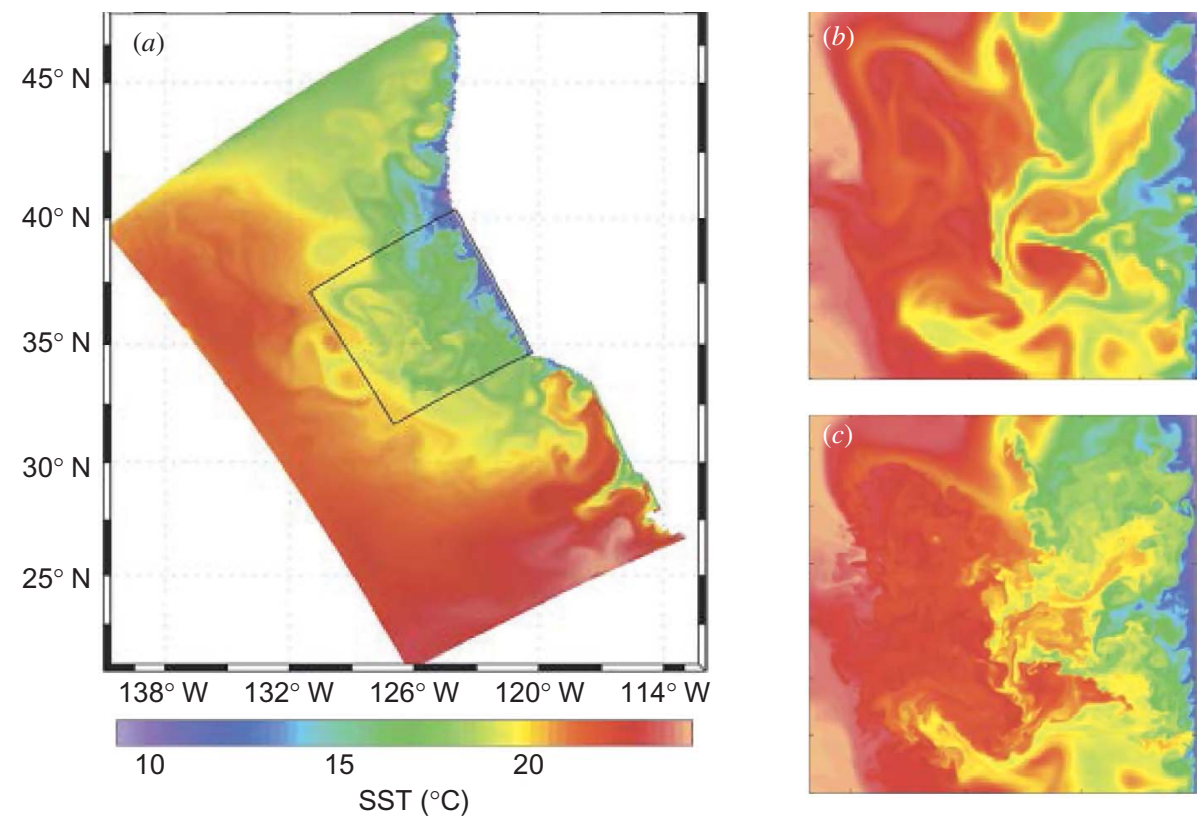

Figure 3. Modelled SST field in the California Upwelling System over a large area (2200 km latitude $\times 1500 \mathrm{~km}$ longitude) $(a)$ and temperature at $10 \mathrm{~m}$ depth over a zoom (shown by the black box, $720 \times 720 \mathrm{~km})$ with a horizontal resolution of $6 \mathrm{~km}(b)$ and $0.75 \mathrm{~km}(c)$ (after Capet et al. 2008).

than the kilometric one. Further, the MISTIGRI TIR observations will be a candidate for assimilation into weather forecasting models, thus improving the latter when simulating both ocean-atmosphere heat exchanges in coastal areas and the subsequent atmospheric dynamics.

\subsubsection{Submesoscale activity in coastal and open ocean}

Submesoscale (1-100 km scale) and mesoscale eddy fields are responsible for most of the kinetic energy of the ocean. At the moment, we can only study mesoscale activity of the ocean with satellite and in situ data. Data are needed to observe submesoscale activity (Fu et al. 2009) characterized by structures (fronts, eddies, vortices, filaments, etc.), which strongly influence vertical transport of different biogeochemical constituents (nutrients, dissolved inorganic carbon, and other tracers). Turbulent transport and energy dissipation processes are important at this scale. This part of the spectrum is simulated with high resolution models in coastal areas (Capet et al. 2008) and in the open ocean (Fu and Ferrari 2008) or observed with airborne TIR cameras (Baschek and Molemaker 2010). For instance, in the study of Capet et al. (2008), the same main mesoscale structures can be identified at two horizontal resolutions ( 6 and $0.75 \mathrm{~km}$ ): the additional smaller (submesoscale) structures visible with the finest resolution at the edges of the mesoscale patterns can increase mixing and vertical velocities (Figure 3). However, there is a need for observations (SST, velocities, etc.) that allow understanding, simulating, and validating the physical and biogeochemical processes involved at this scale. 


\subsubsection{Velocity fields}

Surface velocity fields with high spatial resolution can also be estimated from high spatial and temporal resolution SST images. Among the existing approaches, a new method with only one image at high resolution (MODIS SST data at $4 \mathrm{~km}$ resolution) plus ancillary spatial information at low resolution (surface velocity fields deduced from altimetry and scatterometer at $0.25^{\circ}$ resolution) has been developed and applied on real data (Yahia et al. $2010)$ to estimate velocity field with high horizontal resolution (4 $\mathrm{km}$ resolution). Using such methods, surface velocity fields at very high resolution $(50-100 \mathrm{~m})$ could be estimated with the MISTIGRI data.

\subsubsection{Air-sea gas fluxes and biogeochemical cycles}

The SST provides indirect but essential information in most of the coupled physical/biogeochemical models, especially in coastal areas. Indeed, strong gradients in temperature are usually present in such regions. For example, in upwelling areas, cold SST associated with enriched nutrient waters influences the air-sea greenhouse gas fluxes ( $\mathrm{N}_{2} \mathrm{O}$ (nitrous oxide), $\mathrm{CO}_{2}$ (carbon dioxide), and $\mathrm{CH}_{4}$ (methane), etc.) through thermodynamic and biological processes, as well as nitrogen transfers within the coastal area and towards the open ocean (Gutknecht et al. 2011). River discharges with warm/cold and enriched nutrients and organic matter waters can significantly impact productivity and nitrogen/carbon biogeochemical cycles (Huret et al. 2005) as well as marine resources.

\subsubsection{Monitoring of the coastal ocean}

A number of applications are expected such as (1) the monitoring of pollutant discharge from the rivers and estuaries into the coastal area; (2) the monitoring of exchanges (heat, pollutants, etc.) over the tidally portion of rivers, estuaries, and wetland; (3) the detection of fresh water resurgences; (4) the monitoring of lagunaes; (5) the monitoring of water quality; (6) the detection of algae blooms, etc. For example, high spatial resolution TIR data could provide valuable information when monitoring and studying oil spill (Grierson 1998). An example of application is multitemporal observations collected with the MASTER (MODIS ASTER airborne simulator) sensor during the BP/Gulf of Mexico oil spill in 2010 (http://masterweb.jpl.nasa.gov/data).

\subsubsection{Continental waters (lakes and rivers)}

Surface water temperature of lakes has been defined as an essential climate variable by the Global Climate Observing System (GCOS). It is planned to introduce this parameter in the future lakes and reservoirs international database (Hydrolare, http://www.hydrolare.ru/ index.php; Hydroweb, http://www.legos.obs-mip.fr/en/soa/hydrologie/hydroweb/) hosted by the State Institute of Hydrology of St Petersburg and LEGOS for at least the 150 lakes of the GTN-L (Global Terrestrial Network for Lakes) list. The high spatial resolution of the MISTIGRI data will also be used in a variety of other applications, from process studies of continental waters (lake and rivers) to operational assimilation by numerical prediction systems of continental waters that deal with confluence of rivers and lakes, thermal industrial plumes detection, and monitoring of floods (Hamblin et al. 2002; Reinart and Reynold 2008). 


\subsection{Other applications}

Additionally to the applications described above, and that are the main objectives for which the MISTIGRI mission has been designed, high temporal/spatial resolution TIR remote sensing has a wide range of other potential applications. A few examples are given below.

In the field of volcanology, the monitoring of the surface temperature over the $8-12 \mu \mathrm{m}$ window provides information about volcanic activity, and thermal anomalies often reveal to be precursor signals about eruptions (Wright et al. 2002). The TIR measurements may also help detect volcanic ashes and sulphur dioxide $\left(\mathrm{SO}_{2}\right)$ plumes (Realmuto, Sutton, and Elias 1997; Prata and Kerkmann 2007). Some studies also show that thermal anomalies detected from satellite show potential as precursors to the earthquake activity (Tronin 1996; Wei et al. 2009).

Surface and subsurface coalmine fires are a serious problem in most major coalproducing countries of the world, not only from an economic viewpoint but also in terms of environmental pollution and impact on human life. The detection of subsurface coal fires from daytime observations is a delicate task because of difficulties in discriminating fire-induced and solar-induced heating processes. However, this detection can be improved by using night-time imagery (Mansor et al. 1994; Kuenzer et al. 2008), where high spatial resolution MISTIGRI observations would be of great interest.

By providing up-to-date environmental information, remote-sensing data create an important opportunity to evaluate risk areas or to determine the spatial distribution for some epidemic outbreaks that affect human health. Several diseases can be analysed using remote sensing, such as soil and waterborne diseases, cholera, and schistosomiasis (Beck, Lobitz, and Wood 2000). One of the main variables to be considered when performing such studies is LST (or SST), where the latter can be used over land surfaces in conjunction with vegetation indices (e.g. NDVI) to characterize vegetation amount and environmental conditions (e.g. thermal and hydric status, micrometeorological conditions).

\section{Mission requirements}

\subsection{Spatial resolution}

The choice of the spatial resolution is guided by several contradictory constraints discussed below. On the one hand, resolution must be high enough for making possible the extraction of a significant number of 'pure' (i.e. non-mixed) pixels per field or surface type. This classically imposes an upper limit to the pixel size that should not be exceeded, and that depends upon both the type of studied landscape and the typical size of the ground units met on the images. On the other hand, the combination of a minimum swath mission requirement with the specifications of the available arrays or matrices of detectors directly imposes a lower limit to the pixel size. Finally, surface temperature displays temporal fluctuations driven by the turbulent atmospheric flow at small scale. These fluctuations can only be compensated by spatial integration over the pixel, which results in a relationship between the resolution and the accuracy of the thermal measurements.

\subsubsection{Upper limit of the pixel size}

Several previous studies provide guidelines to propose a maximum acceptable value for the pixel size. We first can refer to Kustas et al. (2004) who studied the resolution necessary to separate the contribution to actual ET of soybean and corn crops in the Iowa plain, where 
fields range in size from 1 to 150 ha, with a typical size of 25 ha. These authors showed that a resolution less than $100 \mathrm{~m}$ makes discrimination of crops difficult. At the extent of the Walnut Creek Watershed agricultural region in Iowa, French et al. (2005) showed the distributional patterns, characterized with NDVI histograms at different resolutions, significantly changed when downscaling to spatial resolution coarser than the hectometric one. In the case of Texas high plains where the typical size of fields is around $800 \times 800 \mathrm{~m}$, Agam et al. (2007) found that a resolution $\leq 100 \mathrm{~m}$ is required for agricultural applications: such a resolution allows satisfactorily resolving differences between fields and within fields. A similar conclusion was found by Garrigues et al. (2006) who quantified the NDVI spatial heterogeneity for 18 landscapes of the VALERI database (http://w3.avignon.inra. $\mathrm{fr} /$ valeri/). Indeed, they concluded that 'the sufficient pixel size to capture the major part of the spatial variability of the vegetation cover at the landscape scale is estimated to be less than $100 \mathrm{~m}$ '. We can also refer to the recent choice of a $100 \mathrm{~m}$ resolution for the two thermal channels of the TIRS instrument aboard the Landsat Data Continuity Mission (LDCM) mission (Irons 2007; Reuter et al. 2010; Wulder et al. 2011). An additional guideline is provided by a recent analysis of the field sizes within a typical Southwestern France agricultural region (Gers department), according to information obtained from administration in the Common Agriculture policy framework: $75 \%$ of the surface is made of plots larger than $150 \times 150 \mathrm{~m}$, which corresponds to a typical $3 \times 3,50 \mathrm{~m}$ pixel grid.

\subsubsection{Lower limit of the pixel size}

The meteorological forcing variables at the surface level display temporal fluctuations in relation to the turbulence of the atmospheric flow, which results in similar fluctuations of the surface temperature within a continuum of frequencies. The impact of processes in the surface boundary layer prevails for high frequencies, whereas low frequencies are mainly driven by the dynamics of the convective planetary boundary layer. High frequencies correspond to turbulent structures of the size of a few metres and can be smoothed by the spatial integration at the pixel scale provided that the size of the pixel is not too small (the so-called 'ergodicity'). Low frequencies correspond to turbulent structures of the size of a few hundred metres. They cannot be removed or even smoothed, and thus contribute to the uncertainty on instantaneous LST measurements, not specifically for MISTIGRI but for all TIR satellite sensors (possibly excluding geostationary systems with very poor resolution).

Ongoing research is currently conducted to analyse the impact of the spatial resolution on the accuracy of LST measurements. It is based on TIR imagery acquired using a helicopter-borne camera during stationary flights. Aggregation techniques then allow simulating time series of LST at different resolutions. Preliminary results obtained over maritime pine stands (Lagouarde et al. 1997) have revealed that the amplitude of high-frequency fluctuations $(\sim 3 \mathrm{~Hz})$ has been rapidly decreasing from about $1.5^{\circ} \mathrm{C}$ at $\sim 5 \mathrm{~m}$ resolution to $\sim 0.5^{\circ} \mathrm{C}$ at $40 \mathrm{~m}$ and $\sim 0.3^{\circ} \mathrm{C}$ at $200 \mathrm{~m}$. A generalization of these results is expected from new experiments performed in 2010 and 2011 summers over a large range of surfaces (bare soils, pine stands, irrigated maize, vineyards, and urban areas) in Southern France, both in night-time and daytime conditions. Numerical simulations of the atmospheric flow using an improved version of the Advanced Regional Prediction System (ARPS) large-eddy simulation (LES) model developed at the Oklahoma University will also be performed to investigate the impact of the planetary boundary layer structures on the uncertainty on MISTRIGRI instantaneous LST measurements. 


\subsubsection{Trade-off-based proposition for spatial resolution}

The $50 \mathrm{~m}$ resolution, which corresponds to half the LDCM one and to half the $100 \mathrm{~m}$ figure often mentioned by many authors (see Section 3.1.1), allows to access small size fields. It is therefore quite well-adapted to a large panel of land-use types and to a number of regions in the world. Moreover it leads, with the detector of MISTIGRI consisting of a $640 \times 480$ pixel microbolometer array, to a $32 \mathrm{~km}$ swath width quite consistent with those of the Ven $\mu$ s $(27 \mathrm{~km})$ and FORMOSAT-2 $(24 \mathrm{~km})$ missions that have similar combined resolution/revisit objectives over the solar domain. Despite a further analysis of the impact of atmospheric turbulence on the accuracy of measurements still to be performed in detail, the $50 \mathrm{~m}$ spatial resolution has finally been considered as a baseline for the technical design of the mission.

\subsection{Revisit and overpass time}

The choice of the revisit and overpass time is guided by both (i) the probability of cloud-free conditions that determine the potential number of available data and (ii) the performances of the models used for deriving fluxes with the required accuracy.

\subsubsection{Analysis of cloudiness}

For agriculture and water monitoring applications, which are the first priorities of the MISTIGRI mission, users generally consider that it is necessary to fulfil the condition of one TIR cloud-free image available every 5 days. Two complementary studies were recently performed to analyse the cloudiness and compare the availability of data for different revisits (Lagouarde et al. 2011).

- The first one is based on the analysis of hourly solar radiation data from the INRA AGROCLIM database. It was performed on 18 year data sets (1992-2009) of eight stations spread over France, which allows considering different climates. The principle for detecting the presence of clouds consists of applying a threshold criterion on the solar radiation, either on the whole data set (1 day revisit) or after having sampled it for simulating less frequent revisits.

- The second study is based on the analysis of standard MODIS Terra surface reflectance MOD09GA products (https://lpdaac.usgs.gov/products/modis_products_ table/mod09ga) of cloud masks at Europe scale over the period from 2000 to 2009.

The results obtained by both methods are quite comparable, as shown with outcomes from the AGROCLIM database (Figure 4) and those from the MODIS 2000-2008 data set (Figure 5). An average of one set of data per 5 day period can be reached on most of the year with a 2 day revisit only for the Mediterranean location of Avignon (Figure 4). To guide the reader, the availability of data for a 5 day revisit has also been indicated: it is clear that such a revisit frequency is not suited for agricultural and hydrological applications. As expected, we verified that the availability of cloud-free days is divided by 2 and 5 for revisits of 2 and 5 days, respectively, when compared to the 1 day revisit. We could simultaneously study the impact of the time acquisition. For clarity, only the potential data availability for 1000,1200 , and 1400 UTC overpass times for a 1 day revisit are presented in Figure 4. Morning haze and fog are likely to explain the data deficit observed in winter for 1000 UTC. On the other hand, the slight decrease appearing in summer for 1400 UTC could possibly be related to convective clouds development phenomena. Therefore, considering cloudiness only, acquisition around noon should be preferred. But other criteria must 
(a)

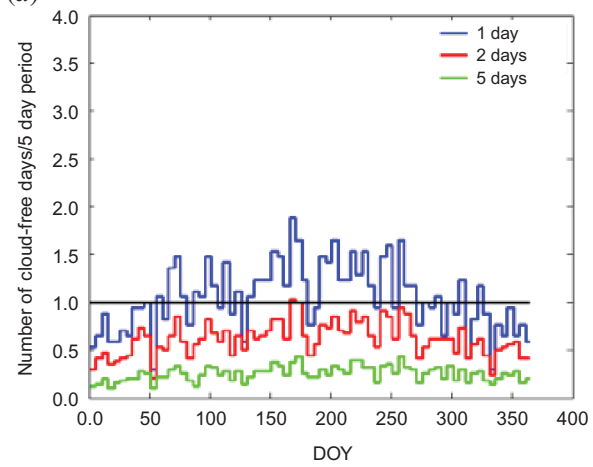

(c)

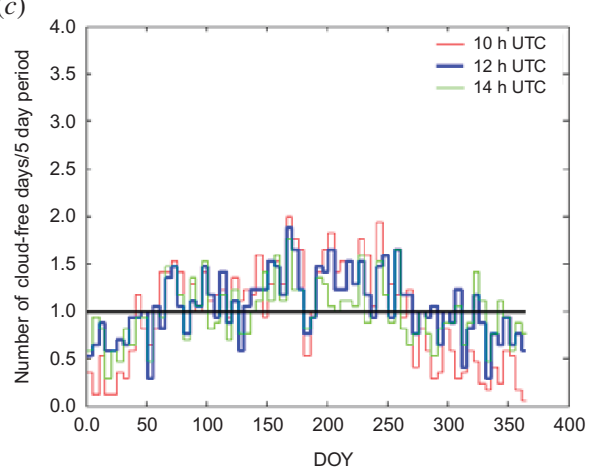

(b)

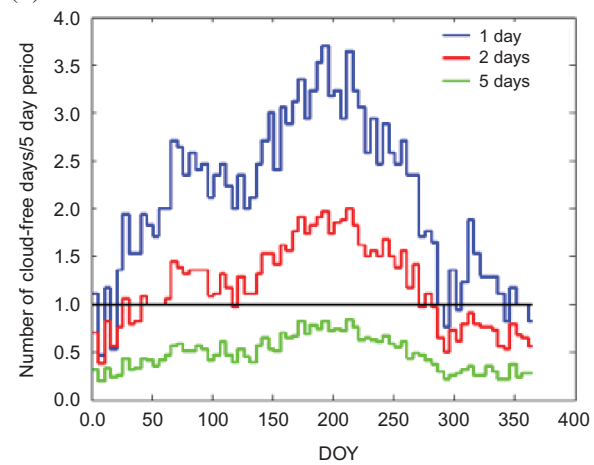

(d)

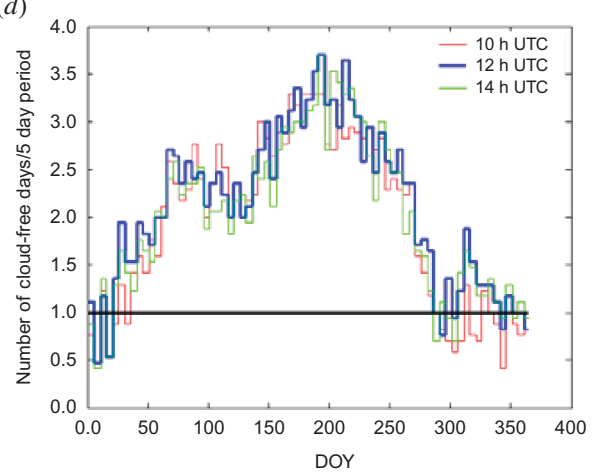

Figure 4. Impact of the revisit time (1, 2, and 5 days) on the availability of data per 5 day period ( $a$ : Rennes, $b$ : Avignon) for an overpass time at $12 \mathrm{~h}$ UTC. Impact of acquisition time (10, 12, and $14 \mathrm{~h}$ UTC) for Rennes $(c)$ and Avignon $(d)$ with a revisit of 1 day. The black line indicates the threshold of one available datum per 5 day period. (DOY = day of year).

also be examined; particularly the sensitivity and accuracy of ET models to the acquisition time (see next section).

Despite some artefacts over mountainous regions due to difficulties in discriminating clouds from snow, the results obtained with MODIS at European scale confirm quite well those derived from the meteorological network data at the scale of France (Figure 5). Another interesting indicator is the average length of periods without data. It brings complementary information, since it allowed one to reduce the weight of partly redundant information available in the case of consecutive clear days. The analysis on Western Europe for spring and summer (Figure 5(c) and $(d)$ ) showed that, except for southern European countries, the average length of periods without data varied on a range between 5 and 10 days for a 1 day revisit, but may reach up to 20 days for a 2 day revisit.

\subsubsection{Impact of the revisit and overpass time on the estimation of ET}

As the number of available cloud-free days sets only an upper limit to the information content that can be retrieved, a more detailed analysis has been undertaken to evaluate the cases when the combination of revisit and cloud frequencies induces long periods without available data, thus preventing us from catching drying periods between water supplies by rain or irrigation. This is currently being done using either long-term time series of simulated 

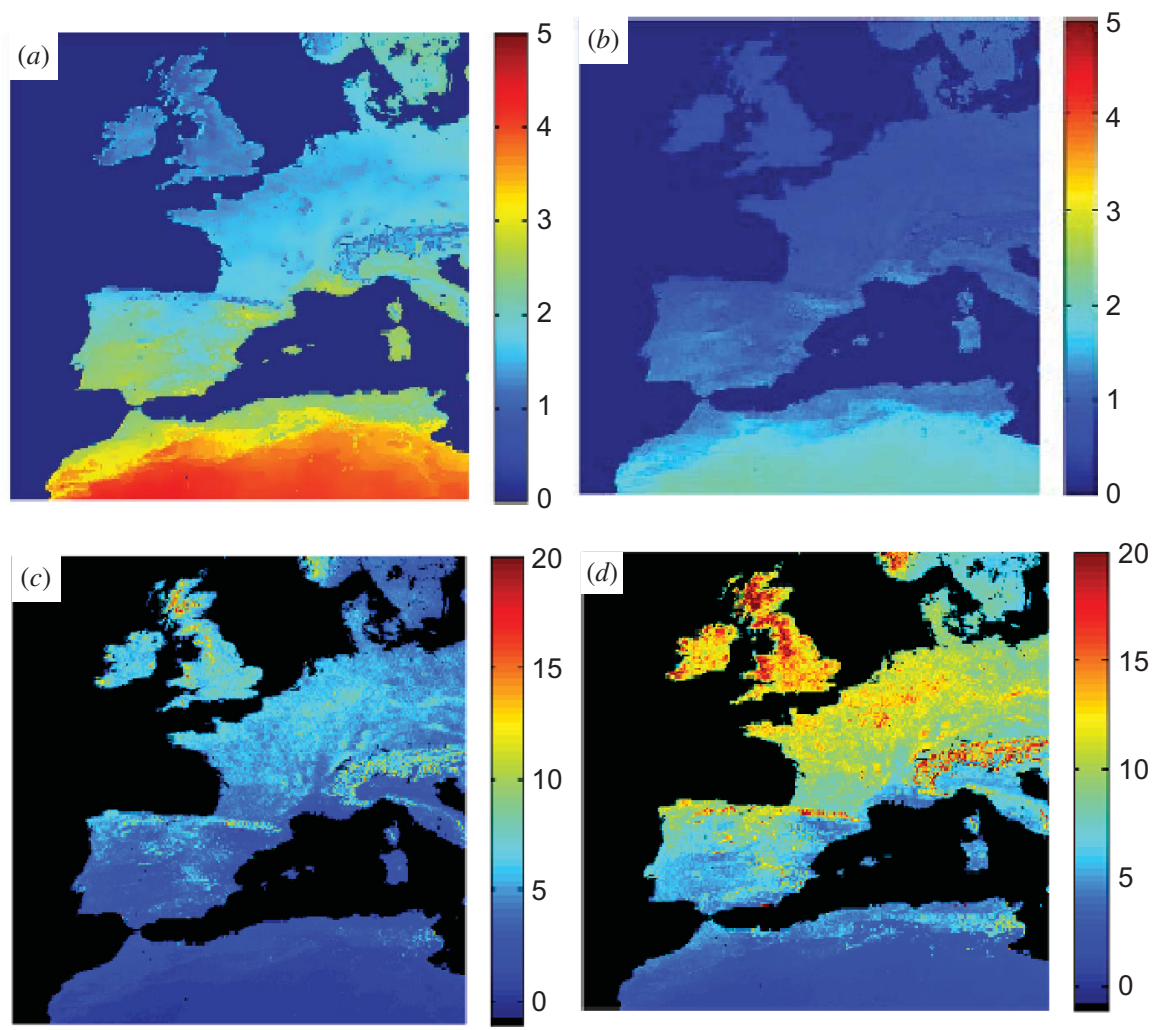

Figure 5. Number of cloud-free days per 5 day period over Europe for a 3 month spring period (1 March-31 May) determined from the analysis of a 9 year data set of MODIS cloud mask product (2000-2008), for 1 day $(a)$ and 2 day $(b)$ revisit times. Average number of days between cloud-free data for the same data set for 1 day $(c)$ and 2 day $(d)$ revisit times.

(synthetic) or experimental ET data collected during long-term experiments. Additionally to the simple criterion of at least one observation per 5 day period, considered in the previous section, an important criterion - particularly sensitive for regions with extensive irrigation - is to have at least one TIR observation per stress period. The preliminary results of these analyses clearly confirm the need of a 1 day revisit.

The choice of the overpass time is guided by the objective of best sensitivity and accuracy on flux estimation. It has also been examined using different results found in the literature. With a coupled SVAT-boundary layer model forced by a sinusoidal diurnal course of net radiation, Gentine, Entekhabi, and Polcher (2011) have shown that latent heat peaks at around 13:00 UTC. Therefore, an overpass time around 13:00 UTC increases the signal to measure and thus the accuracy. This has been confirmed by Crow, Kustas, and Prueger (2008) who assimilated surface temperatures in a SVAT model and showed that performances for root zone soil moisture retrieval also peak at 13:00 UTC. Recent work also shows that instantaneous to daily ET reconstruction methods provide best performance when the overpass time is close to 13:00 UTC (Lagouarde et al. 2011). Finally, the difference between surface $\left(T_{\mathrm{s}}\right)$ and $\operatorname{air}\left(T_{\mathrm{a}}\right)$ temperature is a good indicator of fluxes. An analysis of this difference, performed by Lagouarde and Olioso (1995) from both experimental and simulated data, revealed that acquisition times sooner than 14:00 UTC were best suited to the estimation of ET. 


\subsubsection{Trade-off-based proposition for revisit and overpass time}

In conclusion, all the criteria examined above that combine the data availability (statistical cloudiness analysis) and their ability to derive the fluxes with an acceptable accuracy converge towards a mission specification of a 1 day revisit, and an overpass time in the 12:00-13:00 interval. Finally, this revisit frequency will also allow minimizing the impact of the uncertainties on the LST measurement inherent to the planetary boundary layer turbulence (see Section 3.1.2) by multiplying the available data in assimilation procedures for instance.

\subsection{Spectral bands}

When retrieving surface emissivity and temperature from TIR data, it is necessary to solve the ill-posed problem induced by there being fewer equations (observations over $N$ channels) than unknowns ( $N$ channel emissivities and one surface temperature). The approaches proposed in the literature to overcome the ill-posed problem rely on using spectral, angular, and/or temporal information (Dash et al. 2002; Jacob et al. 2008). First, the consideration of temporal information (i.e. assuming that the emissivity remains constant between consecutive observations) cannot be considered here, since (i) the orbit chosen for MISTIGRI offers a very limited number of locations where day and night tracks cross each other (see Section 5.2) and (ii) MISTIGRI is devoted to the daily monitoring of land surfaces with rapid changes in water status. Second, it is not possible considering methods based on the use of observations around $3.5 \mu \mathrm{m}$, since instrumental constraints hinder the presence of such a channel. Third, the derivation of emissivity from observations over the solar domain is not attractive, since recent works emphasized the lack of correlation between emissivity and biophysical variables (Sobrino et al. 2004a; Sobrino, Jimenez-Munoz, and Paolini 2004b; Dash et al. 2005; French et al. 2008). Therefore, the use of spectral information collected over the TIR domain is preferred, where the Temperature and Emissivity Separation (TES) algorithm has been developed to set minimal emissivity from the spectral variability captured with multispectral TIR observations (Gillespie et al. 1998; Jacob et al. 2004; Sobrino et al. 2007; Sabol et al. 2009).

As a consequence of selecting the TES algorithm, the design of the MISTIGRI TIR bands must cope with different considerations related to (i) atmospheric perturbations, (ii) surface emissivity, and (iii) instrumental noise.

- On the one hand, TIR bands have to be located in spectral regions where atmospheric transmittance is maximal (Figure 6). Such regions cannot be located below $8 \mu \mathrm{m}$ and above $13 \mu \mathrm{m}$, where water vapour makes atmosphere opaque. They cannot either be located around $9.6 \mu \mathrm{m}$ because of ozone absorption that induces a lower atmospheric transmittance. Combined with emissivity close to unity, this explains why the 10-13 $\mu \mathrm{m}$ interval has been widely used for surface temperature measurements (e.g. the spectral configurations of AVHRR, MODIS, AATSR, SEVIRI, etc.).

- On the other hand, the TIR signal is affected by surface emissivity. As compared to the 10-13 $\mu \mathrm{m}$ interval, emissivity between 8.0 and $9.2 \mu \mathrm{m}$ shows lower values and larger variabilities (Schmugge, Hook, and Coll 1998; Schmugge et al. 2002a, 2002b). An example is displayed by Figure 7. Therefore, better spectral emissivity retrieval is expected when considering more channels over both the $8.0-9.2 \mu \mathrm{m}$ and $10-13 \mu \mathrm{m}$ intervals (Payan and Royer 2004).

- Finally, instrumental perturbations constrain the channel widths, as narrower channels make possible finer and richer spectral sampling, but induce a larger instrumental noise. 


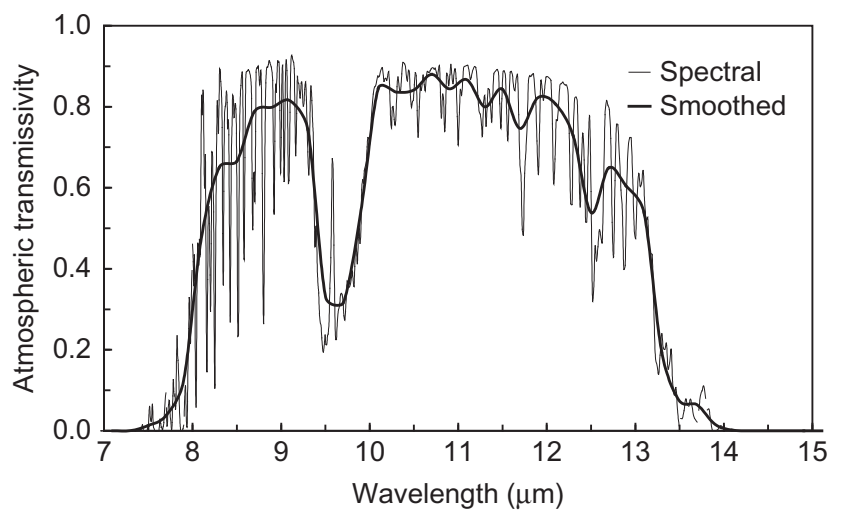

Figure 6. Atmospheric spectral transmittance derived from MODTRAN simulations with a $1 \mathrm{~cm}^{-1}$ spectral resolution.

Note: Observation conditions correspond to a spaceborne sensor with a nadir view angle. Atmospheric conditions correspond to a typical atmospheric profile from the TOVS Initial Guess Retrieval (TIGR) database, with an atmospheric water vapour content of $2.04 \mathrm{~g} \mathrm{~cm}^{-2}$. For clarity, a $0.2 \mu \mathrm{m}$ spectral resolution smoothing is also indicated.

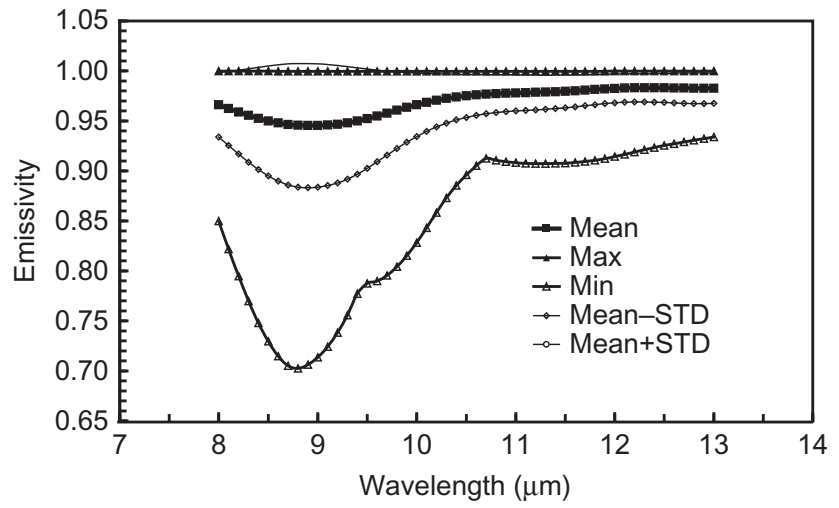

Figure 7. Mean emissivity spectrum for 108 natural samples including rocks, soils, vegetation, water, and ice of the ASTER database.

Note: Maximum, minimum, mean plus standard deviation (STD), and mean minus standard deviation are also plotted.

Designing the MISTIGRI TIR bands for maximizing the TES accuracy is therefore a critical issue. TES has been operationally applied to the five ASTER TIR bands (Abrams 2000), but Gillespie et al. (1998) suggested that TES satisfactorily performs when applied to three or four bands only. Hulley, Hook, and Baldrige (2010) applied TES to the three MODIS TIR bands, and showed that LST retrievals were similar to the MODIS LST products based on a different algorithm. Recent tests performed on a real ASTER image acquired over an agricultural area in Spain confirmed the feasibility of applying TES algorithm to only three bands.

At the present time, the MISTIGRI baseline is four bands centred at 8.6, 9.1, 10.3, and $11.5 \mu \mathrm{m}$. A $1 \mu \mathrm{m}$ bandwidth is recommended for reducing the instrumental noise. Despite separate bands at 8.6 and $9.1 \mu \mathrm{m}$ are supposedly preferable to capture spectral variabilities 
over numerous surfaces (bare soils, rocks, artificial urban materials, etc.), MISTIGRI phase A investigated the relevance of merging these two bands into a single one centred at $8.8 \mu \mathrm{m}$, where the expected benefit is a channel widening to reduce the instrumental noise.

In the VNIR range, four bands have been selected at 450,670,865, and $910 \mathrm{~nm}$, with a higher spatial resolution of $\sim 20 \mathrm{~m}$. The utility of these bands originates in various objectives: (1) registering TIR images, (2) detecting low clouds, (3) estimating integrated water vapour content to be used next for atmospheric corrections of TIR data, (4) estimating vegetation biophysical variables such as LAI and vegetation fraction cover, (5) estimating albedo, (6) characterizing land use, and (7) possibly disaggregating TIR data, etc. Most of these objectives, additional to the retrieval of ET, require VNIR imagery to be acquired simultaneously to TIR ones. For these reasons, using other satellites (Sentinel-2, for instance) cannot replace a VNIR instrument onboard MISTIGRI.

\section{Strategy of the mission}

In parallel with modelling efforts, numerous experimental sites have been established by the scientific community in order to improve our understanding of the exchanges of energy, momentum, and mass $\left(\mathrm{H}_{2} \mathrm{O}\right.$ and other gases such as $\mathrm{CO}_{2}, \mathrm{CH}_{4}, \mathrm{~N}_{2} \mathrm{O}$, etc. $)$ that occur together at the surface as the result of the complex interplays between biotic and abiotic processes. Validation and improvement of the models developed are expected to serve a number of purposes in various fields such as ecology, agronomy, coastal oceanography, meteorology, and climatology. Other experimental sites, usually larger than the previous ones, are used to develop and test applications and services based on Earth Observation satellite data.

MISTIGRI is an experimental scientific mission devoted to elaborate products to improve and validate the models and methodologies proposed by the community, and to evaluate their potential for practical applications. The mission is planned for a duration of life of 5 years. The strategy of the MISTIGRI mission is similar to that of Ven $\mu$ s (http://www.cesbio.ups-tlse.fr/fr/indexvenus.html), and associates a spaceborne system with experimental sites at ground. The baseline acquisition strategy for the selected sites and transects will be to observe them every day during the mission life. The choice of the sites will be based on an international call for proposal of sites. The scientific communities have already established networks of experimental sites, where intensive ground measurements and survey are carried out continuously, in the framework of long-term programmes for monitoring climate, ecology, or hydrology processes. Examples are FLUXNET (http://fluxnet.ornl.gov), ICOS (http://www.icos-infrastructure. eu/), LTER (http://www.Iternet.edu/), the French national ORE programme (http://www. ore.fr/), GEWEX programmes (http://www.gewex.org/projects.html), the NEESPI initiative (http://neespi.org/), etc. The typical size of the sites in relation to the surface processes under study should be at least $25 \times 25 \mathrm{~km}$. This is suitable for most typical farming regions in the world, even those including very large fields, such as in the USA (Irons 2007). It is also well suited to monitor most large towns (apart from large capital cities), to observe the main gradients from continent to open sea in most areas, and also to monitor great lakes. The proposed $50 \mathrm{~m}$ spatial resolution and the resulting $32 \mathrm{~km}$ swath width (Section 3.1.3) allow one to fulfil the minimum site size requirement quite well.

A second kind of acquisition aims at acquiring systematic time series of high ground resolution archives over a sample of regions that are facing or are expected to face severe changes driven by climatic, human, or internal dynamics forces. The focus will be on regions that exhibit strong gradients in terms of ecosystem types and climate. Such regions 
include, for example, the northern latitudes, with transition from boreal forest to tundra, the monsoon regime areas with rapid variation of precipitation amounts like in Sahel, and altitudinal gradients with transition from plains to mountains in many places around the world. The MISTIGRI acquisition plan will include several long transects in boreal zones in order to monitor the seasonal and interannual variabilities. These transects can be made of continuous acquisitions of several hundreds of kilometres long, or may consist of samples (about $25 \times 25 \mathrm{~km}$ ) distributed over transects.

Acquisitions will also be performed at night for some particular applications, in particular over urban areas (analysis of UHI, of heat losses by buildings, etc.), or for measurements of SST when the water temperature profile is much more homogeneous.

\section{Proposed mission architecture}

The mission architecture presented hereafter is the result of technical studies and trade-off led by CNES with the support of the French company Thales Alenia Space Cannes as far as the Payload concept is concerned. A MISTIGRI phase 0 was performed over 2008 and early 2009, and a phase A activity conducted until end of 2011. The MISTIGRI phase 0 led to the choice of a technical baseline that consists of a TIR camera using an 'off the shelf' microbolometer (ULIS Company, Grenoble, France) mounted on a bus satellite with a maximal reuse of the microsatellite platform MYRIADE product line. The CNES started the development of the MYRIADE spacecraft bus in 1998 to provide effective, low-cost access to space. The microbolometer solution is able to fulfil the primary radiometric requirements without demanding any cooling system. A classical VNIR instrument is associated with the TIR one. Most of the MISTIGRI system elements involved in this baseline have a strong heritage, which should significantly reduce programme costs and technical and schedule risks. The key parameters of the mission are listed in Table 1, and are commented in the sections below.

\subsection{Payload and instrumental concepts}

\subsubsection{VNIR instrument}

The VNIR instrument aboard MISTIGRI gathers four channels at 450, 670, 865, and $910 \mathrm{~nm}$. The two channels at 670 and $865 \mathrm{~nm}$ are primarily devoted to the characterization of vegetation. The channel at $450 \mathrm{~nm}$, in the blue region of the spectrum, aims to detect low clouds (Hagolle et al. 2010). The ratio between channels at 910 and $865 \mathrm{~nm}$ can be used to estimate the atmospheric integrated water vapour content and to improve the atmospheric correction of the thermal bands (Sobrino, El-Kharraz, and Li 2003). The four bands, or a subgroup of them, can be used to derive surface albedo (Jacob et al. 2002b, 2002c). The use of VNIR observations in combination with TIR data requires simultaneous acquisition (see Section 3.3), but a spatial resolution much finer than that of the TIR sensor is not necessary. The resolution of VNIR data has been set to $20 \mathrm{~m}$, which is easy to achieve. It makes the design of the VNIR instrument based on a charge-coupled device (CCD) detector rather simple and easy to build.

\subsubsection{TIR focal plane}

After a detailed study, the $640 \times 480$ microbolometer array with a pixel pitch of $25 \mu \mathrm{m}$ developed by the French Company ULIS was finally selected for the TIR instrument. For a $50 \mathrm{~m}$ spatial resolution, it corresponds to a nominal $32 \mathrm{~km}$ swath. Although the sensitivity 
Table 1. Key parameters of the MISTIGRI mission.

\begin{tabular}{|c|c|c|}
\hline Parameter & \multicolumn{2}{|c|}{ Value } \\
\hline Orbit altitude $(\mathrm{km})$ & \multicolumn{2}{|c|}{561} \\
\hline Swath width (km) & \multicolumn{2}{|c|}{32} \\
\hline $\begin{array}{l}\text { Depointing and accessibility to } \\
\text { ground sites }\end{array}$ & \multicolumn{2}{|c|}{ Satellite roll and pitch } \\
\hline & VNIR & TIR \\
\hline Spectral bands & $450,670,865$, and $910 \mathrm{~nm}$ & $8.6,9.1,10.3$, and $11.5 \mu \mathrm{m}$ \\
\hline Resolution (m) & 20 & 50 \\
\hline Optical design & Dioptric & Catadioptric (Cassegrain) \\
\hline Entrance pupil diameter (mm) & 60 & 300 \\
\hline Focal length (mm) & 365 & 281 \\
\hline Aperture & $\mathrm{F} / 6.1$ & $\mathrm{~F} / 0.94$ \\
\hline Detector type & Quadrilinear CCD & Uncooled microbolometer array \\
\hline Imaging mode & Pushbroom & Pushbroom TDI-like binning \\
\hline TDI-like images/lines & - & 30 \\
\hline Satellite slowdown & & 1.92 \\
\hline MTF at Nyquist & 0.2 & $0.1-0.3$ \\
\hline NedT at $290 \mathrm{~K}$ & - & $0.2-0.5 \mathrm{~K}$ \\
\hline Absolute accuracy & - & $1 \mathrm{~K}$ \\
\hline SNR at minimum radiance & $70-180$ & \\
\hline Mass & & $0 \mathrm{~kg}$ \\
\hline Power consumption & & $0 \mathrm{~W}$ \\
\hline
\end{tabular}

Note: NedT, Noise equivalent differential temperature.

of microbolometers is less than that of cryogenic detectors, the main advantage of such detectors lies in the fact that they do not need any cooling system.

The microbolometer thermal time constant introduces a constraint to the satellite operation. Indeed, the sampling time needs to be longer than the time constant in order to achieve good modulation transfer function (MTF) and linearity performances. According to the characteristics of the detectors, the sampling time must range between 1.5 and 2.0 times the time constant, i.e. a minimum of $13.8 \mathrm{~ms}$ in the present case. This over-sampling is made possible by a 'satellite slowdown' obtained by varying the pitch angle of the platform all along the acquisition of the image. Given the $561 \mathrm{~km}$ orbit altitude, it results in a satellite slowdown factor of about 1.92 .

High-resolution missions moreover require adapted technical solutions in order to achieve the specified radiometric performances. Time delay integration (TDI) is a commonly used technique, whereby the signal of a ground pixel on the detector is continuously integrated over several lines in synchronization with the satellite movement. Thus, the signal of a ground pixel is increased, achieving a better signal-to-noise ratio (SNR). For MISTIGRI a TDI-like binning rate of 30 lines is considered.

The spectral selection is done by thin-layer interference filters placed close to each other in front of the detector. The filters must be wide enough (30 lines) to acquire the same line of the scene 30 times, thus allowing the required TDI-like image binning.

\subsubsection{TIR optical design}

The optical design is based on a classical catadioptric Cassegrain telescope, consisting of primary and secondary mirrors associated with six lenses. The materials selected for the 
lenses are germanium and zinc selenide ( $\mathrm{ZnSe}$ ). They are chosen to ensure good transmission and aberration correction over the whole spectral domain. The entrance pupil diameter is $300 \mathrm{~mm}$ and this pupil is located in front of the primary mirror.

\subsubsection{Mechanical and thermal designs}

The mechanical design of the instrument has been done taking into account the constraints imposed by MYRIADE bus in its standard configuration. The payload comprises the following main subassemblies: VNIR telescope and focal plane, TIR telescope and focal plane, four electrical units for payload control, video electronics of each camera and their power supply unit, the TIR calibration subsystem, and two radiators, one for the focal plane and another for the electronics. A computer-aided design view of the preliminary mechanical design is given in Figure 8.

\subsubsection{TIR calibration}

Calibration systems for infrared instruments generally include blackbodies at their entrance so that the entire optical chain is calibrated. Given the TIR instrument size, this solution would require a too voluminous blackbody, which is incompatible with the MYRIADE platform. Instead, it is proposed to implement two small blackbodies in front of an intermediate pupil located after the first lens. These consist of two shutters whose temperatures are regulated in a small heated box and which are successively placed in front of the pupil. This solution allows reducing the size of the blackbodies. Two temperatures are needed to calibrate the instrument and retrieve the gain and offset values to be applied during image processing. The values of the two temperatures have been set at 293 and $313 \mathrm{~K}$ to avoid cooling and to keep a sufficient $20 \mathrm{~K}$ range for accuracy purpose. They could still be adjusted. Besides, deep space calibration will also be done in order to assess optics transmission and emissivity drift in-flight not directly taken into account with the calibration system because of the position of the blackbodies behind the front optics. Since there is no folding mirror in the design, deep space steering is achieved by satellite manoeuvring. This operation should not be performed frequently (a few months).

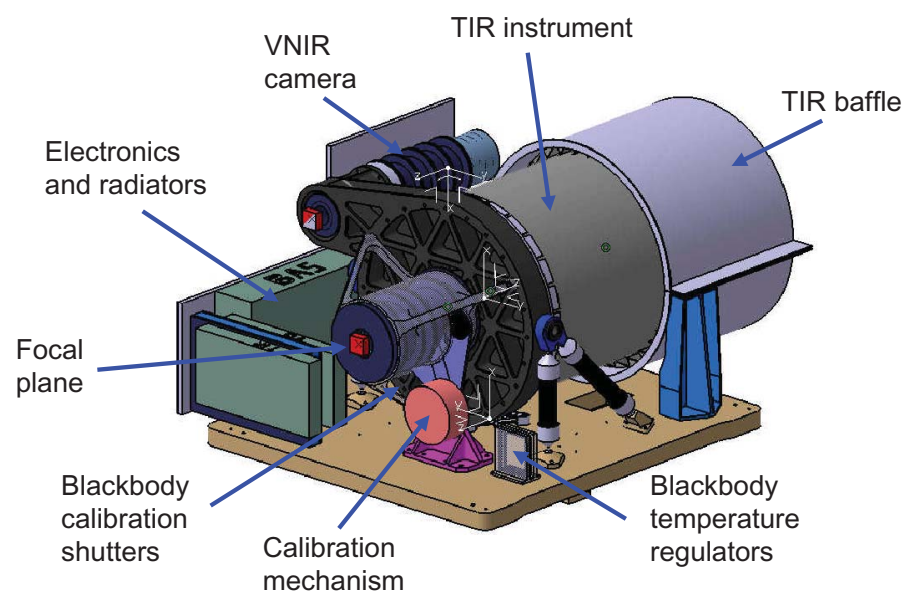

Figure 8. TIR and VNIR instrumental layout. 


\subsection{Coverage and accessibility}

The 1 day revisit delay requirement implies to choose a Sun-synchronous orbit at $561 \mathrm{~km}$ altitude. This orbit provides 15 different ground tracks, each of them having one daylight descending track and one ascending night track, which cross on a very limited number of locations.

\subsubsection{Earth coverage and acquisition capacity}

The $32 \mathrm{~km}$ swath width obviously reduces the Earth's surface extent to be imaged. Accessibility of the ground sites is obtained by rotating the platform, across (roll rotation) or along the track (pitch rotation). The Earth's coverage is therefore limited by two constraints.

First, the maximum roll angle allowed for across-track depointing define a strip each side of the track in which sites are potentially accessible. For instance, allowing a maximum roll angle of $30^{\circ}$, the potential accessibility is about $34 \%$ at $45^{\circ}$ latitude, as illustrated in Figure 9 . It could be increased by extending the roll angle to $40^{\circ}$ or more, which would require directional and atmospheric effects to be carefully accounted for.

The second limitation to the acquisition capacity lies in (i) the time duration including tranquilization required to achieve the manoeuvres (pitch and roll angles changes) between sites, and in (ii) by the picture duration taking into account the slowdown ratio. Manoeuvre delay is driven by the satellite agility obtained through reaction wheels; it depends on the satellite inertia and on the reaction wheels torque and kinetic moment capability. For agility purpose, the standard MYRIADE wheels will be replaced by more powerful wheels.

With such a configuration and given the satellite agility, the MISTIGRI mission will be able to fulfil the following observation scenario:

- independent sites $(25 \times 25 \mathrm{~km}$ at least $)$ or contiguous transects up to $700 \mathrm{~km}$ long (this length depending upon the satellite slowdown ratio), during day time or nighttime;

- possibility of observing up to 98 sites on the day time and night-time of the same orbit; and

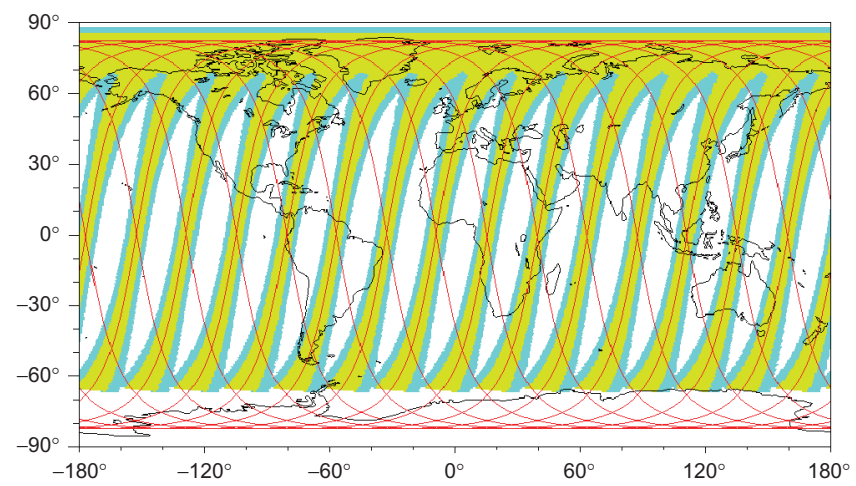

Figure 9. Potential Earth coverage for the $561 \mathrm{~km}$ MISTIGRI Sun-synchronous orbit, and for $30^{\circ}$ (yellow) and $45^{\circ}$ (green) off-track viewing capacities. 
- given that there are 15 different tracks in 1 day, and assuming a 29\% land/ocean surface ratio, the number of potentially observable sites could reach about 425 per day, provided suitably located on the land surface.

These figures are to be confirmed, and studies are currently conducted for considering realistic scenario with actual site locations. Nevertheless, despite that they will impose some constraints for the selection of ground experimental sites, these accessibility capacities remain quite compatible with a scientific experimental mission objective.

\subsubsection{Directional configuration}

As for the Venus satellite mission (Crebassol et al. 2010), each site will be systematically observed with the same viewing geometry (zenith and azimuth viewing angles). This will largely ease the analysis of observation time series by reducing the viewing directional effects, despite remaining effects induced by changes in solar zenith and azimuth angles throughout the year. In this way, the recent progress on the knowledge of TIR directional anisotropy (Pinheiro et al. 2004; Huang, Liu, and Qin 2009; Van der Tol et al. 2009; Lagouarde et al. 2010) should significantly contribute to improve the interpretation of the MISTIGRI off-nadir observations.

\subsection{Satellite}

The MISTIGRI mission is based on the use of the microsatellite platform MYRIADE. MYRIADE is a multipurpose flight-proven platform developed by CNES in partnership with the industry. In January 2011, 10 satellites have already been launched since 2004. This leads to a 40 year experience of in-orbit cumulated life time with this bus, including 6 years for the first satellite launched (DEMETER mission). In addition, nine satellites are currently being developed.

The MISTIGRI spacecraft general architecture is based on the last version of the standard MYRIADE bus (Figure 10). This bus features a new mechanical structure, enabling a total satellite mass of at least $200 \mathrm{~kg}$ compatible with different launchers. The structure is currently being developed, the CNES TARANIS mission (dedicated to the magnetosphere observation) being planned to be the first user (with a launch by 2015). The only noticeable

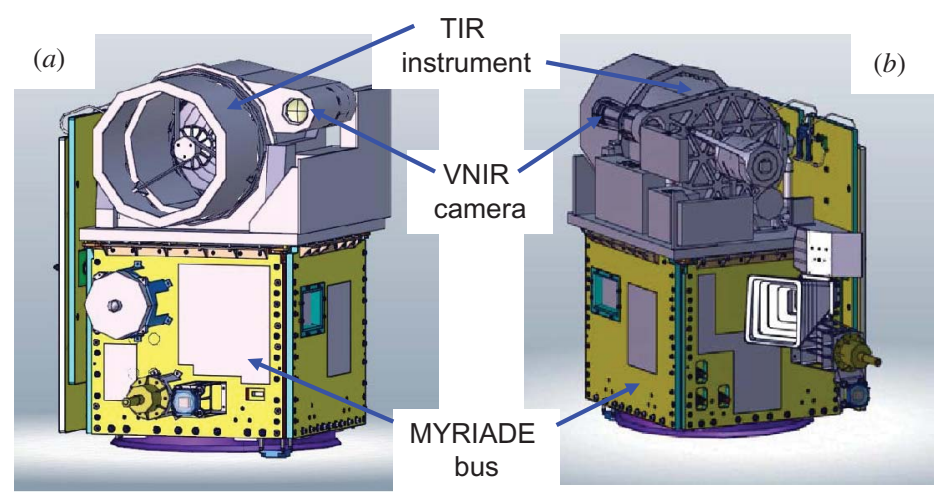

Figure 10. MISTIGRI satellite view ( $a$ : front, $b$ : back) showing the VNIR-TIR instrument installed on the MYRIADE platform (in yellow). 
MISTIGRI adaptation of the standard MYRIADE version relies on the reaction wheels, which will be replaced by more powerful ones (torque multiplied by about 5) for agility purposes.

The scientific data produced by TIR and VNIR instruments are stored in the $16 \mathrm{~Gb}$ MYRIADE mass memory. Downloading of these data is realized through an X band link based on the MYRIADE high-rate telemetry (16.8 $\left.\mathrm{Mb} \mathrm{s}^{-1}\right)$. The MYRIADE equipment allows fulfilling the MISTIGRI mission needs with a large margin.

\subsection{Ground segment}

The MISTIGRI ground segment system is based on existing knowhow and well-tried technologies (Figure 11). It classically encompasses several components.

(1) A flight operation segment is in charge of programming, controlling, and monitoring the satellite. It is based on the generic CNES microsatellite ground segment (MIGS), already existing and being used for several years. This MIGS features a control centre with the classical functions such as telemetry processing and archiving, remote control generation and sending, etc. The communications with the satellite are in $\mathrm{S}$ band.

(2) A payload data ground segment (PDGS) is in charge of image data processing, image quality monitoring, and MISTIGRI product distribution to users. It will be based on the Ven $\mu$ s Scientific Mission Ground Segment (Ven $\mu$ s SMIGS), which is today in phase of integration within the rest of the Ven $\mu$ s system. It is interfaced with servers devoted to products distribution.

(3) The satellite data will be sent to an existing X band receiving station (or Earth Terminal, ET). At this point, some interfacing developments will be necessary: a MISTIGRI receiving kit adapted to the selected Earth Terminal(s) will have to be built, as has been done for Ven $\mu$ s. Currently, an X band ET is in use at CNES in Toulouse; in the forthcoming years, another X band ET might be constructed in Northern Europe.

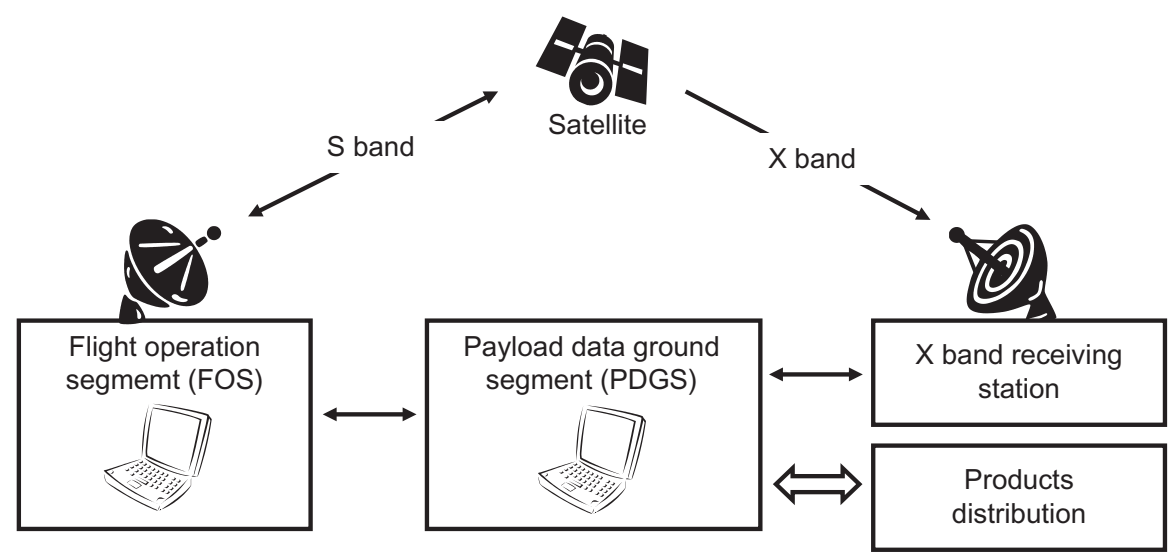

Figure 11. Schematic ground segment design. 


\section{Conclusion}

By filling the gap between high temporal/low spatial resolutions, on the one hand, and high spatial/low temporal resolutions, on the other hand, which is currently a critical issue in the context of the TIR missions, MISTIGRI is expected to bring original information with a 1 day revisit and $\sim 50 \mathrm{~m}$ resolution. The general scientific objectives of the mission deal with the monitoring of continental biosphere, of biogeochemical cycles, and of surface energy budgets, where applications become more and more crucial in the context of climate change and increasing anthropogenic pressure (heat waves, extremes events such as droughts and floods, etc.). The first priority of the mission is devoted to agriculture, water management, and hydrology. A second set of priorities deals with urban areas, with applications to energy consumption management, heat islands, and dynamics of the urban boundary layer for studying diffusion of pollutants. Third, significant progress is expected in the monitoring of coastal areas and continental waters. Aside from these three main fields of applications, other research activities could benefit from MISTIGRI data and a few examples such as volcanology have been mentioned.

The mission requirements have been described. The instrument design has been motivated by recent and ongoing studies that deal with critical issues such as spatial resolution, overpass time, revisiting frequency, and spectral configuration over the TIR domain. MISTIGRI is an experimental mission devoted to the validation of methodologies and to the development of TIR-derived products. Its strategy is similar to that of Ven $\mu$ s, since (i) it is based on a microsatellite and (ii) it associates a network of ground experimental sites located all over the world and monitored by well-identified scientific teams.

The scientific context is favourable, MISTIGRI being supported by an active scientific community that has large experience and a good maturity level in TIR remote sensing from the view point of modelling, experimental studies, as well as spatial projects such as IRSUTE (Seguin et al. 1999) and SEXTET at CNES, PRISM and SPECTRA at ESA, FOCUS and BIRD at DLR, and FUEGO in Spain. The feasibility of MISTIGRI relies on the recent technological progress (uncooled microbolometers among others), and on the fact that the MISTIGRI architecture is built on elements that (i) have a strong heritage (platform) and (ii) can be easily derived from other missions (e.g. the Ven $\mu$ s ground segment). Finally, dealing with the general context of global change international programmes, it appears that the development or reinforcement of long-term federative initiatives and programmes (such as FLUXNET, ICOS, GMES, etc.) makes urgent an innovative experimental mission in the TIR such as MISTIGRI.

\section{Acknowledgements}

This work was supported by the Centre National d'Etudes Spatiales (CNES/TOSCA). It also received support from Programme National de Télédétection Spatiale (PNTS) and Institut National des Sciences de 1'Univers (INSU/CNRS) in France, and CDTI and Spanish Ministry of Science and Innovation (EODIX, project AYA2008-0595-C04-01) in Spain.

\section{References}

Abrams, M. 2000. "The Advanced Spaceborne Thermal Emission and Reflection Radiometer (ASTER): Data Products for the High Spatial Resolution Imager on NASA's Terra Platform." International Journal of Remote Sensing 21: 847-59.

Agam, N., W. P. Kustas, M. C. Anderson, F. Li, and P. Colaizzi. 2007. "Utility of Thermal Sharpening over Texas High Plains Irrigated Agricultural Fields." Journal of Geophysical Research 112: D19110. doi:10.1029/2007 JD008407. 
Allen, R. G., M. Tasumi, and R. Trezza. 2007. "Satellite-Based Energy Balance for Mapping Evapotranspiration with Internalized Calibration (METRIC)-Model." ASCE Journal of Irrigation and Drainage Engineering 133: 380-94.

Alletto, L., Y. Coquet, P. Benoit, and V. Bergheaud. 2006. "Effects of Temperature and Water Content on Degradation of Isoproturon in Three Soil Profiles." Chemosphere 64: 1053-61.

Arnfield, A. J. 2003. "Two Decades of Urban Climate Research: A Review of Turbulence, Exchanges of Energy and Water, and the Urban Heat Island." International Journal of Climatology 23: 1-26.

Baschek, B., and M. J. Molemaker. 2010. "Aerial and In Situ Measurements of Submesoscale Eddies, Fronts and Filaments." 2010 Ocean Science Meeting, Portland, OR, February 22-26, 2010.

Bastiaanssen, W. G. M., M. Menenti, R. A. Feddes, and A. A. M. Holtslag. 1998. "A Remote Sensing Surface Energy Balance Algorithm for Land (SEBAL) -2: Validation." Journal of Hydrology 213: 198-212.

Bastiaanssen, W. G. M., E. J. M. Noordman, H. Pelgrum, G. Davids, and R. G. Allen. 2005. "SEBAL for Spatially Distributed ET under Actual Management and Growing Conditions." ASCE Journal of Irrigation and Drainage Engineering 131: 85-93.

Beck, L. R., B. M. Lobitz, and B. L. Wood. 2000. "Remote Sensing and Human Health: New Sensors and New Opportunities." Emerging Infectious Diseases 6: 217-27.

Becker, F., and Z.-L. Li. 1990. "Temperature-Independent Spectral Indices in Thermal Infrared Bands." Remote Sensing of Environment 32: 17-33.

Belot, A. 2007. "Simulation des Échanges D'énergie et de Masse d'un Couvert Végétal: Développement et Validation D'un Modèle Quasi 3D, DART-EB." PhD thesis, Paul Sabatier University Toulouse, $199 \mathrm{p}$.

Boulet, G., A. Chehbouni, P. Gentine, B. Duchemin, J. Ezzahar, and R. Hadria. 2007. "Monitoring Water Stress Using Time Series of Observed to Unstressed Surface Temperature Difference." Agricultural and Forest Meteorology 146: 159-72.

Brutsaert, W. 1986. "Catchment-Scale Evaporation and the Atmospheric Boundary Layer." Water Resource Research 11: 39-45.

Capet, X., J. C. McWilliams, M. J. Molemaker, and A. F. Shchepetkin. 2008. "Mesoscale to Submesoscale Transition in the California Current System, Part I: Flow Structure, Eddy Flux, and Observational Tests." Journal of Physical Oceanography 38: 29-43.

Carlson, T. N. 2007. "An Overview of the "Triangle Method" for Estimating Surface Evapotranspiration and Soil Moisture from Satellite Imagery." Sensors 7: 1612-29.

Carlson, T. N., and S. T. Arthur. 2000. "The Impact of Land Use-Land Cover Changes Due to Urbanization on Surface Microclimate and Hydrology: A Satellite Perspective." Global and Planetary Change 25: 49-65.

Carlson, T. N., J. K. Dodd, S. G. Benjamin, and J. N. Cooper. 1981. "Satellite Estimation of the Surface Energy Balance, Moisture Availability and Thermal Inertia." Journal of Applied Meteorology 20: 67-87.

Chelton, D. B., M. G. Schlax, and R. M. Samelson. 2007. "Summertime Coupling between Sea Surface Temperature and Wind Stress in the California Current System." Journal of Physical Oceanography 37: 495-517.

Comiso, J. C. 2003. "Warming Trends in the Arctic from Clear Sky Satellite Observations." Journal of Climate 16: 3498-510.

Cortinovis, J., F. Solmon, D. Serça, C. Sarrat, and R. Rosset. 2004. “A Simple Modeling Approach to Study the Regional Impact of a Mediterranean Forest Isoprene Emission on Anthropogenic Plumes." Atmospheric Chemistry and Physics Discussions 4: 7691-724.

Coudert, B., and C. Ottlé. 2007. "An Improved SVAT Model Calibration Strategy Based on the Optimisation of Surface Temperature Temporal Dynamics." Geophysics Research Letters 34: L04402.

Courault, D., F. Jacob, V. Benoit, M. Weiss, O. Marloie, J.-F. Hanocq, G. Dedieu, P. Gouaux, M. Gay, and A. French. 2009. "Influence of Agricultural Practices on Micrometeorological Spatial Variations at Local and Regional Scales." International Journal of Remote Sensing 30: 1183-205.

Courault, D., B. Seguin, and A. Olioso. 2005. "Review on Estimation of Evapotranspiration from Remote Sensing Data: From Empirical to Numerical Modeling Approaches." Irrigation and Drainage Systems 19: 223-49.

Crebassol, P., P. Ferrier, G. Dedieu, O. Hagolle, B. Fougnie, F. Tinto, Y. Yaniv, and J. Herscovitz. 2010. "VEN $\mu$ S (Vegetation and Environment Monitoring on a New Micro Satellite)." In Small Satellite Missions for Earth Observation, edited by R. Sandau, H.-P. Roeser, and A. Valenzuela, 47-65. Springer: Berlin. 
Crow, W. T., W. P. Kustas, and J. H. Prueger. 2008. "Monitoring Root-Zone Soil Moisture through the Assimilation of a Thermal Remote Sensing-Based Soil Moisture Proxy into a Water Balance Model." Remote Sensing of Environment 112: 1268-81.

Dash, P., F.-M. Gottsche, F.-S. Olesen, and H. Fischer. 2002. "Land Surface Temperature and Emissivity Estimation from Passive Sensor Data: Theory and Practice-Current Trends." International Journal of Remote Sensing 23: 2563-94.

Dash, P., F. M. Göttsche, F. S. Olesen, and H. Fischer. 2005. "Separating Surface Emissivity and Temperature Using Two-Channel Spectral Indices and Emissivity Composites and Comparison with a Vegetation Fraction Method." Remote Sensing of Environment 96: 1-17.

Donlon C. J., K. S. Casey, C. Gentemann, P. LeBorgne, I. S. Robinson, R. W. Reynolds, C. Merchant, D. Llewellyn-Jones, P. J. Minnett, J. F. Piolle, P. Cornillon, N. Rayner, T. Brandon, J. Vazquez, E. Armstrong, H. Beggs, I. Barton, G. Wick, S. Castro, J. Hoeyer, D. May, O. A. Arino, D. J. Poulter, R. Evans, C. T. Mutlow, A. W. Bingham, and A. Harris. 2009. "Successes and Challenges for the Modern Sea Surface Temperature Observing System." In Proceedings of OceanObs'09: Sustained Ocean Observations and Information for Society (Vol. 2), edited by J. Hall, D. E. Harrison, and D. Stammer, Venice, Italy, September 21-25, 2009, 45 p. ESA Publication WPP-306, doi:10.5270/OceanObs09.cwp.24.

Dousset, B., F. Gourmelon, K. Laaidi, A. Zeghnoun, E. Giraudet, P. Bretin, E. Mauri, and S. Vandertorren. 2011. "Satellite Monitoring of Summer Heat Waves in Paris Metropolitan Area." International Journal of Climatology 31: 313-23.

Fensholt, R., I. Sandholt, M. S. Rasmussen, S. Stisen, and A. Diouf. 2006. "Evaluation of Satellite Based Primary Production Modelling in the Semi-Arid Sahel." Remote Sensing of Environment 105: 173-88.

Fontanilles, G., X. Briottet, S. Fabre, and T. Trémas. 2008. “Thermal Infrared Radiance Simulation with Aggregation Modelling (TITAN): An Infrared Radiative Transfer Model for Heterogeneous 3-D Surface - Application over Urban Areas." Applied Optics 47: 5799-810.

French, A. N., F. Jacob, M. C. Anderson, W. P. Kustas, W. Timmermans, A. Gieske, B. Su, H. Su, M. F. McCabe, F. Li, J. Prueger, and N. Brunsell. 2005. "Surface Energy Fluxes with the Advanced Spaceborne Thermal Emission and Reflection Radiometer (ASTER) at the Iowa 2002 SMACEX Site (USA).” Remote Sensing of Environment 99: 55-65.

French, A. N., T. Schmugge, J. Ritchie, A. Hsu, F. Jacob, and K. Ogawa. 2008. "Detecting Landcover Change at Jornada, New Mexico with ASTER Emissivities." Remote Sensing of Environment 112: $1730-48$.

Fu, L.-L., D. Alsdrof, E. Rodriguez, R. Morrow, N. Mogand, J. Lambin, P. Vaze, and T. Lafon. 2009. "The WOT (Surface Water and Ocean Topography) Mission: Spaceborne Radar Interferometry for Oceanographic and Hydrological Applications." In Proceedings of OceanObs'09: Sustained Ocean Observations and Information for Society (Vol. 2), edited by J. Hall, D. E. Harrison, and D. Stammer, Venice, Italy, September 21-25, 2009, 16 p. ESA Publication WPP-306, doi:10.5270/OceanObs09.cwp.33.

Fu, L.-L., and R. Ferrari. 2008. "Observing Oceanic Submesoscale Processes from Space.” Eos 89: 488.

Galleguillos, M., F. Jacob, L. Prévot, A. French, and P. Lagacherie. 2011b. "Comparison of Two Temperature Differencing Methods to Estimate Daily Evapotranspiration over a Mediterranean Watershed from ASTER Data." Remote Sensing of Environment 115: 1326-40.

Galleguillos, M., F. Jacob, L. Prévot, P. Lagacherie, and S. Liang. 2011a. "Mapping Daily Evapotranspiration over a Mediterranean Vineyard Watershed." IEEE - Geoscience and Remote Sensing Letters 8: 168-72.

Garrigues, S., D. Allard, F. Baret, and M. Weiss. 2006. "Quantifying Spatial Heterogeneity at the Landscape Scale Using Variogram Models.” Remote Sensing of Environment 103: 81-96.

Gentine, P., D. Entekhabi, and J. Polcher. 2011. "The Diurnal Behavior of Evaporative Fraction in the Soil-Vegetation-Atmospheric Boundary Layer Continuum." Journal of Hydrometeorology. doi:10.1175/2011JHM1261.1.

Gillespie, A., S. Rokugawa, T. Matsunaga, J. S. Cothern, S. Hook, and A. Kahle. 1998. "A Temperature and Emissivity Separation Algorithm for Advanced Spaceborne Thermal Emission and Reflection Radiometer (ASTER) Images." IEEE Transactions on Geoscience and Remote Sensing 36: 1113-26.

Grierson, I. T. 1998. "Use of Airborne Thermal Imagery to Detect and Monitor Inshore Oil Spill Residues during Darkness Hours." Environmental Management 22: 905-12. 
Gutknecht, E., I. Dadou, B. Le Vu, G. Cambon, J. Sudre, V. Garçon, E. Machu, T. Rixen, A. Kock, A. Flohr, A. Paulmier, and G. Lavik. 2011. "Nitrogen Transfers and Air-Sea $\mathrm{N}_{2} \mathrm{O}$ Fluxes in the Upwelling Off Namibia Within the Oxygen Minimum Zone: A 3-D Model Approach." Biogeosciences Discussions 8: 3537-618.

Gómez, M., A. Olioso, J. A. Sobrino, and F. Jacob. 2005. "Retrieval of Evapotranspiration over the Alpilles/ReSeDA Experimental Site Using Airborne POLDER Sensor and a Thermal Camera." Remote Sensing of Environment 96: 399-408. doi:10.1016/j.rse.2005.03.006.

Hachem, S., M. Allard, and C. R. Duguay. 2009. "Using the MODIS Land Surface Temperature Product for Mapping Permafrost: An Application to Northern Quebec and Labrador, Canada." Permafrost and Periglacial Processes 20: 407-16.

Hagolle, O., M. Huc, D. Villa Pascual, and G. Dedieu. 2010. "A Multi-Temporal Method for Cloud Detection, Applied to FORMOSAT-2, VEN $\mu$ S, LANDSAT and SENTINEL-2 Images." Remote Sensing of Environment 114: 1747-55.

Hamblin, P. F., P. Verburg, P. Roebber, H. A. Bootsma, and R. E. Hecky. 2002. "Observations, Evaporation and Preliminary Modelling of Overlake Meteorology on Large African Lakes." In Advance in Global Change Research, The East African Great Lakes: Limnology, Palaelimnology and Biodiversity, edited by E. O. Odada and D. O. Olago, Vol. 12, 121-51. Dordrecht: Kluwer Academic Publishers.

Huang, H. G., Q.-H. Liu, and W. H. Qin. 2009. "Coupling the CUPID and TRGM Models to Study the Temporal Variations of Thermal Emission Directionality of Crop Canopies." PIERS Proceedings, Beijing, March 23-27, 1558-62. Cambridge, MA: The Electromagnetics Academy Publisher.

Hulley, G., S. J. Hook, and A. M. Baldrige. 2010. "Investigating the Effects of Soil Moisture on Thermal Infrared Land Surface Temperature and Emissivity Using Satellite Retrievals and Laboratory Measurements." Remote Sensing of Environment 114: 1480-93.

Huret, M., I. Dadou, F. Dumas, P. Lazure, and V. Garçon. 2005. "Coupling Physical and Biogeochemical Processes in the Rio De La Plata Plume." Continental Shelf Research 25: 629-53.

Hénon, A. 2008. "Températures Mesurées, Modélisées, et Observées par Télédétection Infrarouge, dans la Canopée Urbaine: Modélisation Aéro-Thermo-Radiative des Flux de Chaleur Urbains." $\mathrm{PhD}$ thesis, Ecole Centrale Nantes et Université Nantes, $230 \mathrm{p}$.

Hénon, A., J.-P. Lagouarde, P. G. Mestayer, and D. Groleau. 2009. "High Resolution Surface Temperature and Urban Thermal Anisotropy Simulations: Validation by Airborne Remote Sensing Data from the CAPITOUL Experiment." AMS 89th Annual Meeting/8th Symposium on the Urban Environment, Phoenix, AZ, January 11-15.

IPCC. 2007. "Contribution of Working Groups I, II and III to the Fourth Assessment, Report of the Intergovernmental Panel on Climate Change." In Climate Change 2007: Synthesis Report, edited by R. K. Pachauri and A. Reisinger, 104 p. Geneva: IPCC.

Inamdar, A. K., and A. French. 2009. "Disaggregation of GOES Land Surface Temperatures Using Surface Emissivity." Geophysics Research Letters 36: D02408. doi:10.1029/2008GL036544.

Inamdar, A. K., A. French, S. Hook, G. Vaughan, and W. Luckett. 2008. "Land Surface Temperature Retrieval at High Spatial and Temporal Resolutions over the Southwestern United States." Journal of Geophysical Research 113: D07107. doi:10.1029/2007JD009048.

Irons, J. 2007. Status of the Landsat Data Continuity Mission and Related Activities. NARSEC 2007, Santa Fe, New Mexico. Accessed March 6, 2007. http:/science.nature.nps.gov/im/monitor/ meetings/NARSEC_2007/presentations/08_JIrons_Day1_Landsat.pdf.

Jacob, F., A. Olioso, X. F. Gu, Z. Su, and B. Seguin. 2002a. "Mapping Surface Fluxes Using Airborne Visible, Near Infrared, Thermal Infrared Remote Sensing Data and a Spatialized Surface Energy Balance Model." Agronomie 22: 669-80.

Jacob, F., A. Olioso, M. Weiss, F. Baret, and O. Hautecoeur. 2002b. "Mapping Short-Wave Albedo of Agricultural Surfaces Using Airborne PolDER Data." Remote Sensing of Environment 80: 36-46.

Jacob, F., F. Petitcolin, T. Schmugge, E. Vermote, A. French, and K. Ogawa. 2004. "Comparison of Land Surface Emissivity and Radiometric Temperature Derived from MODIS and ASTER Sensors." Remote Sensing of Environment 90: 137-52.

Jacob, F., T. Schmugge, A. Olioso, A. French, D. Courault, K. Ogawa, F. Petitcolin, A. Chehbouni, A. Pinheiro, and J. Privette. 2008. "Modeling and Inversion in Thermal Infrared Remote Sensing over Vegetated Land Surfaces." In Advances in Land Remote Sensing: System, Modeling, Inversion, and Application, edited by S. Liang. Springer. Vol. 354, 245-92. http://www.springer. com/earth+sciences+and+geography/remote+sensing/book/978-1-4020-6449-4. 
Jacob, F., M. Weiss, A. Olioso, and A. French. 2002c. "Assessing the Narrowband to Broadband Conversion to Estimate Visible, Near Infrared and Shortwave Apparent Albedo from Airborne PoIDER Data." Agronomie 22: 537-46.

Jang, J. D., A. A. Viau, and F. Anctil. 2006. "Thermal-Water Stress Index from Satellite Images." International Journal of Remote Sensing 27: 1619-39.

Jiang, L., and S. Islam. 1999. "A Methodology for Estimation of Surface Evapotranspiration over Large Areas Using Remote Sensing Observations." Geophysics Research Letters 26, no. 17: 2773-6. doi:10.1029/1999GL006049.

Kalma, J. D., T. R. McVicar, and M. F. McCabe. 2008. "Estimating Land Surface Evaporation: A Review of Methods Using Remotely Sensed Surface Temperature Data." Surveys in Geophysics 29: 421-69.

Kato, S., and Y. Yamaguchi. 2005. "Analysis of Urban Heat-Island Effect Using ASTER and ETM+ Data: Separation of Anthropogenic Heat Discharge and Natural Heat Radiation from Sensible Heat Flux." Remote Sensing of Environment 99: 44-54.

Kramm, G., N. Beier, T. Foken, H. Müller, P. Schröder, and W. Seiler. 1996. "A SVAT Scheme for $\mathrm{NO}, \mathrm{NO}_{2}$, and 03-Model Description and Test Results." Meteorological Atmospheres Physics 61: $89-106$.

Kuenzer, C., C. Hecker, J. Zhang, S. Wessling, and W. Wagner. 2008. "The Potential of Multidiurnal MODIS Thermal Band Data for Coal Fire Detection.” International Journal of Remote Sensing 9: 923-44. doi:10.1080/01431160701352147.

Kurz, B. 2009. "Modélisation de L'anisotropie Directionnelle de la Température de Surface: Application au cas des Milieux Forestiers et Urbains." PhD thesis, Université de Toulouse, 144 p.

Kustas, W. P., F. Li, T. J. Jackson, J. H. Prueger, J. I. MacPherson, and M. Wolde. 2004. "Effects of Remote Sensing Pixel Resolution on Modelled Energy Flux Variability of Croplands in Iowa." Remote Sensing of Environment 92: 535-47.

Lagouarde, J. P., H. Ballans, P. Moreau, D. Guyon, and D. Coraboeuf. 2000. "Experimental Study of Brightness Surface Temperature Angular Variations of Maritime Pine (Pinus pinaster) Stands." Remote Sensing of Environment 72: 17-34.

Lagouarde, J. P., S. Dubreton, P. Moreau, and D. Guyon. 1997. "Analyse De L'ergodicité De La Température De Surface Sur Des Couverts Forestiers À Diverses Résolutions Spatiales." In Seventh Symposium International on Physical Measurements and Signatures in Remote Sensing, edited by G. Guyot, T. Phulpin, and ISPRS, 303-10. Rotterdam: Balkema.

Lagouarde, J.-P., A. Hénon, B. Kurz, P. Moreau, M. Irvine, J. Voogt, and P. Mestayer. 2010. "Modelling Daytime Thermal Infrared Directional Anisotropy over Toulouse City Centre." Remote Sensing of Environment 114: 87-105.

Lagouarde, J. P., and A. Olioso. 1995. "Interest of Mid-Morning Acquisition of Surface Temperature for Deriving Surface Fluxes." Remote Sensing Reviews 12: 287-309.

Lagouarde, J.-P., A. Olioso, G. Boulet, B. Coudert, S. Dayau, S. Castillo, M. Weiss, J.-L. Roujean, E. Delogu, and N. Puche. 2011. "Defining the Revisit Frequency for the MISTIGRI Project of a Satellite Mission in the Thermal Infrared." Proceeding of the 3rd International Symposium 'Recent advances in quantitative remote sensing', edited by J. Sobrino, 824-9. Valencia (Spain): Universitat de Valencia.

Louchart, X., and M. Voltz. 2007. "Aging Effects on the Availability of Herbicides to Runoff Transfer." Environmental Science \& Technology 41: 1137-41.

Mansor, S. B., A. P. Cracknell, B. V. Shilin, and V. I. Gornyi. 1994. "Monitoring of Underground Coal Fires Using Thermal Infrared Data." International Journal of Remote Sensing 15: 1675-85.

Martilli, A., A. Clappier, and M. W. Rotach. 2002. "An Urban Surface Exchange Parameterisation for Mesoscale Models." Bound Layer Meteorological 104: 261-304.

Masson, V. 2006. "Urban Surface Modelling and the Meso-Scale Impact of Cities." Theoretical and Applied Climatology 84: 35-45.

Merlin, O., B. Duchemin, O. Hagolle, F. Jacob, B. Coudert, G. Chehbouni, G. Dedieu, J. Garatuza, and Y. Kerr. 2010. "Disaggregation of MODIS Surface Temperature over an Agricultural Area Using a Time Series of Formosat-2 Images." Remote Sensing of Environment 114: 2500-12.

Merlin, O., F. Jacob, J.-P. Wigneron, J. Walker, and G. Chehbouni. 2012. "Multi-Dimensional Disaggregation of Land Surface Temperature Using High-Resolution Red, Near-Infrared, Shortwave-Infrared and Microwave-L Bands." IEEE Transactions on Geoscience and Remote Sensing 50: 1864-80. 
Moran, M., T. Clarke, Y. Inoue, and A. Vidal. 1994. "Estimating Crop Water Deficit Using Relation between Surface-Air Temperature and Spectral Vegetation Index.” Remote Sensing of Environment 49: 246-63.

Moran, M., A. Rahman, J. Washburne, D. Goodrich, M. Weltz, and W. Kustas. 1996. "Combining the Penman- Monteith Equation with Measurements of Surface Temperature and Reflectance to Estimate Evaporation Rates of Semiarid Grassland." Agricultural and Forest Meteorology 80: $87-109$.

Oku, Y., H. Shikawa, and S. U. Zhongbo. 2007. "Estimation of Land Surface Heat Fluxes over the Tibetan Plateau Using GMS Data." Journal of Applied Meteorology and Climatology A 46: 183-95.

Olioso, A., H. Chauki, D. Courault, and J.-P. Wigneron. 1999. "Estimation of Evapotranspiration and Photosynthesis by Assimilation of Remote Sensing Data into SVAT Models." Remote Sensing of Environment 68: 341-56.

Olioso, A., Y. Inoue, S. Ortega-Farias, J. Demarty, J.-P. Wigneron, I. Braud, F. Jacob, P. Lecharpentier, C. Ottlé, J.-C. Calvet, and N. Brisson. 2005. "Future Directions for Advanced Evapotranspiration Modeling: Assimilation of Remote Sensing Data into Crop Simulation Models and SVAT Models." Irrigation and Drainage Systems 19: 377-412.

Ottlé, C., D. Vidal-Madjar, and G. Girard. 1989. "Remote Sensing Applications to Hydrological Modeling." Journal of Hydrology 105: 369-84.

Payan, V., and A. Royer. 2004. "Analysis of the Temperature Emissivity Separation (TES) Algorithm Applicability and Sensitivity." International Journal of Remote Sensing 25: 15-37.

Pellenq, J., and G. Boulet. 2002. "A Methodology to Test the Pertinence of Remote-Sensing Data Assimilation into Vegetation Models for Water and Energy Exchange at the Land Surface." Agronomie 24: 197-204.

Pigeon, G., D. Legain, P. Durand, and V. Masson. 2007. "Anthropogenic Heat Release in an Old European City (Toulouse, France)." International Journal of Climatology 27: 1969-81.

Pinheiro, A., J. Privette, R. Mahoney, and C. Tucker. 2004. "Directional Effects in a Daily AVHRR Land Surface Temperature Dataset over Africa." IEEE Transactions on Geoscience and Remote Sensing 42: 1941-54.

Prata, A. J., and J. Kerkmann. 2007. "Simultaneous Retrieval of Volcanic Ash and $\mathrm{SO}_{2}$ Using MSG-SEVIRI Measurements." Geophysical Research Letters 34: L05813. doi:10.1029/2006GL028691.

Realmuto, V., A. Sutton, and T. Elias. 1997. "Multispectral Thermal Infrared Mapping of Sulfur Dioxide Plumes: A Case Study from the East Rift Zone of Kilauea Volcano, Hawaii.” Journal of Geophysical Research 102, B7: 15057-72.

Reinart, A., and M. Reynold. 2008. "Mapping Surface Temperature in Large Lakes with Modis Data." Remote Sensing of Environment 112: 603-11.

Reuter, R., C. Richardson, J. Irons, R. Allen, M. Anderson, J. Budinoff, G. Casto, C. Coltharp, P. Finneran, B. Forsbacka, T. Hale, T. Jennings, M. Jhabvala, A. Lunsford, G. Magnuson, R. Mills, T. Morse, V. Otero, S. Rohrbach, R. Smith, T. Sullivan, Z. Tesfaye, K. Thome, G. Unger, and P. Whitehouse. 2010. "The Thermal Infrared Sensor on the Landsat Data Continuity Mission." IGARSS 2010, 754-757. doi:10.1109/IGARSS.2010.5653746.

Roerink, G. J., B. Su, and M. Menenti. 2000. "S-SEBI a Simple Remote Sensing Algorithm to Estimate the Surface Energy Balance." Physics and Chemistry of the Earth, Part B: Hydrology, Oceans and Atmosphere 25: 147-57.

Roth, M., T. R. Oke, and W. J. Emery. 1989. "Satellite-Derived Urban Heat Islands from Three Coastal Cities and the Utilization of Such Data in Urban Climatology." International Journal of Remote Sensing 10: 1699-720.

Sabol, D. E., A. R. Gillespie, E. Abbott, and G. Yamada. 2009. "Field Validation of the ASTER Temperature-Emissivity Separation Algorithm." Remote Sensing of Environment 113: 2328-44.

Schmugge, T., A. French, J. C. Ritchie, A. Rango, and H. Pelgrum. 2002a. "Temperature and Emissivity Separation from Multispectral Thermal Infrared Observations." Remote Sensing of Environment 79: 189-98.

Schmugge, T., S. J. Hook, and C. Coll. 1998. "Recovering Surface Temperature and Emissivity from Thermal Infrared Multispectral Data." Remote Sensing of Environment 65: 121-31.

Schmugge, T. J., K. Ogawa, F. Jacob, and A. French. 2002b. "Quantitative Estimates of Land Surface Emissivity Using ASTER Data." EOS Transactions, American Geophysical Union 83, no. 47: 62B-06. 
Schuurmans, J. M., P. A. Troch, A. A. Veldhuizen, W. G. M. Bastiaanssen, and M. F. P. Bierkens. 2003. "Assimilation of Remotely Sensed Latent Heat Flux in a Distributed Hydrological Model." Advances in Water Resources 26: 151-9. doi:10.1016/S0309-1708(02)00089-1.

Seguin, B., F. Becker, T. Phulpin, X. F. Gu, G. Guyot, Y. Kerr, C. King, J. P. Lagouarde, C. Ottlè, M. P. Stoll, A. Tabbagh, and A. Vidal. 1999. "IRSUTE: A Minisatellite Project for Land Surface Heat Flux Estimation, from Field to Regional Scale." Remote Sensing of Environment 68: 357-69.

Sobrino, J. A., J. El-Kharraz, and Z. L. Li. 2003. "Surface Temperature and Water Vapor Retrieval from MODIS Data." International Journal of Remote Sensing 24: 5161-82.

Sobrino, J. A., J. C. Jimenez-Munoz, L. Balick, A. R. Gillespie, D. A. Sabol, and W. T. Gustafson. 2007. "Accuracy of Aster Level-2 Thermal-Infrared Standard Products of an Agricultural Area in Spain." Remote Sensing of Environment 106: 146-53.

Sobrino, J., J. Jimenez-Munoz, J. El-Kharraz, M. Gomez, M. Romaguera, and G. Soria. 2004a. "Single-Channel and Two-Channel Methods for Land Surface Temperature Retrieval from DAIS Data and Its Application to the Barrax Site." International Journal of Remote Sensing 25: 215-30.

Sobrino, J., J. Jimenez-Munoz, and L. Paolini. 2004b. "Land Surface Temperature Retrieval from Landsat TM 5." Remote Sensing of Environment 90: 434-40.

Sobrino, J. A., J. C. Jiménez-Muñoz, G. Sòria, M. Gómez, A. Barella-Ortiz, M. Romaguera, M. Zaragoza, Y. Julien, J. Cuenca, M. Atitar, V. Hidalgo, B. Franch, C. Mattar, A. Ruescas, L. Morales, A. Gillespie, L. Balick, Z. Su, F. Nerry, L. Peres, and R. Libonati. 2008. "Thermal Remote Sensing in the Framework of the SEN2FLEX Project: Field Measurements, Airborne Data and Applications." International Journal of Remote Sensing 29: 4961-91.

Soux, A., J. A. Voogt, and T. Oke. 2004. "A Model to Calculate What a Remote Sensor 'Sees' of an Urban Surface.” Boundary-Layer Meteorology 111: 109-32.

$\mathrm{Su}$, Z. 2002. "The Surface Energy Balance System (SEBS) for Estimation of Turbulent Fluxes." Hydrology and Earth System Sciences 6: 85-99.

Tang, R. L., Z. L. Li, and B. H. Tang. 2010. "An Application of the Ts-VI Triangle Method with Enhanced Edges Determination for Evapotranspiration Estimation from MODIS Data in Arid and Semi-Arid Regions: Implementation and Validation." Remote Sensing of Environment 114: $540-51$.

Tronin, A. A. 1996. "Satellite Thermal Survey - a New Tool for the Studies of Seismoactive Regions." International Journal of Remote Sensing 17: 1439-55.

Van der Kwast, J., W. Timmermans, A. Giesk, Z. Su, A. Olioso, L. Jia, J. Elbers, D. Karssenberg, and S. de Jong. 2009. "Evaluation of the Surface Energy Balance System (SEBS) Applied to ASTER Imagery with Flux-Measurements at the SPARC 2004 Site (Barrax, Spain).” Hydrology and Earth System Sciences 13: 1337-47.

Van der Tol, C., W. Verhoef, J. Timmermans, A. Verhoef, and Z. Su. 2009. "An Integrated Model of Soil-Canopy Spectral Radiances, Photosynthesis, Fluorescence, Temperature and Energy Balance." Biogeosciences 6: 3109-29.

Voogt, J. A., and T. R. Oke. 2003. "Thermal Remote Sensing of Urban Climates." Remote Sensing of Environment 86: 370-84.

Wei, L., J. Guo, J. Liu, Z. Lu, H. Li, and H. Cai. 2009. "Satellite Thermal Infrared Earthquake Precursor to the Wenchuan $M_{\mathrm{s}} 8.0$ Earthquake in Sichuan, China, and Its Analysis on Geo-Dynamics." Acta Geologica Sinica - English Edition 83: 767-75. doi:10.1111/j.17556724.2009.00100.x.

Wright, R., L. Flynn, H. Garberl, A. Harris, and E. Pilger. 2002. "Automated Volcanic Eruption Detection Using MODIS.” Remote Sensing of Environment 82: 135-255.

Wulder, M. A., J. C. White, J. G. Masek, J. Dwyer, and D. P. Roy. 2011. "Continuity of Landsat Observations: Short Term Considerations." Remote Sensing of Environment 115: 747-51.

Yahia, H., J. Sudre, C. Pottier, and V. Garçon. 2010. "Motion Analysis in Oceanographic Satellite Images Using Multiscale Methods and the Energy Cascade." Pattern Recognition 43: 3591-604. doi:10.1016/j.patcog.2010.04.011. 